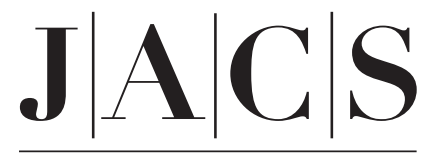

A R T I C L E S

Published on Web 06/15/2005

\title{
Linear Artificial Molecular Muscles
}

\author{
Yi Liu, ${ }^{\dagger}$ Amar H. Flood, ${ }^{\dagger}$ Paul A. Bonvallet, ${ }^{\dagger}, \|$ Scott A. Vignon, ${ }^{\dagger}$ Brian H. Northrop, ${ }^{\dagger}$ \\ Hsian-Rong Tseng, ${ }^{\dagger}$ Jan O. Jeppesen,\# Tony J. Huang, ${ }^{\perp}$ Branden Brough, ${ }^{\perp}$ \\ Marko Baller,§ Sergei Magonov, ${ }^{\S}$ Santiago D. Solares, ${ }^{\ddagger}$ William A. Goddard, ${ }^{\ddagger}$ \\ Chih-Ming Ho, ${ }^{*}, \perp$ and J. Fraser Stoddart*, ${ }^{*}$ \\ Contribution from the California NanoSystems Institute (CNSI), Department of Chemistry and \\ Biochemistry, Institute for Cell Mimetic Space Exploration (CMISE), and Mechanical and \\ Aerospace Engineering Department, University of California, Los Angeles, California 90095, \\ Department of Chemistry, University of Southern Denmark, Odense University, Denmark, Veeco \\ Instruments, 112 Robin Hills Road, Santa Barbara, California 93117, and Materials and \\ Process Simulation Center, Division of Chemistry and Chemical Engineering, California \\ Institute of Technology, Pasadena, California 91125
}

Received February 20, 2005; E-mail: chihming@ucla.edu; stoddart@chem.ucla.edu

\begin{abstract}
Two switchable, palindromically constituted bistable [3]rotaxanes have been designed and synthesized with a pair of mechanically mobile rings encircling a single dumbbell. These designs are reminiscent of a "molecular muscle" for the purposes of amplifying and harnessing molecular mechanical motions. The location of the two cyclobis(paraquat-p-phenylene) $\left(\mathrm{CBPQT}^{4+}\right)$ rings can be controlled to be on either tetrathiafulvalene (TTF) or naphthalene (NP) stations, either chemically ( ${ }^{1} \mathrm{H}$ NMR spectroscopy) or electrochemically (cyclic voltammetry), such that switching of inter-ring distances from 4.2 to $1.4 \mathrm{~nm}$ mimics the contraction and extension of skeletal muscle, albeit on a shorter length scale. Fast scan-rate cyclic voltammetry at low temperatures reveals stepwise oxidations and movements of one-half of the [3]rotaxane and then of the other, a process that appears to be concerted at room temperature. The active form of the bistable [3]rotaxane bears disulfide tethers attached covalently to both of the CBPQT ${ }^{4+}$ ring components for the purpose of its self-assembly onto a gold surface. An array of flexible microcantilever beams, each coated on one side with a monolayer of 6 billion of the active bistable [3]rotaxane molecules, undergoes controllable and reversible bending up and down when it is exposed to the synchronous addition of aqueous chemical oxidants and reductants. The beam bending is correlated with flexing of the surfacebound molecular muscles, whereas a monolayer of the dumbbell alone is inactive under the same conditions. This observation supports the hypothesis that the cumulative nanoscale movements within surface-bound "molecular muscles" can be harnessed to perform larger-scale mechanical work.
\end{abstract}

\section{Introduction}

As microscale electronic ${ }^{1}$ and mechanical devices ${ }^{2}$ continue to be miniaturized, it has become clear that conventional "topdown" lithographic techniques are not suited by themselves for the fabrication of nanoscale components. Thus, a "bottom-up" involvement, ${ }^{3}$ centered upon the design and manipulation of molecular assemblies - both biological ${ }^{4,5}$ and artificial ${ }^{6-8}$ - has emerged as a potential tool for the development of nanoelec-

The California NanoSystems Institute and Department of Chemistry and Biochemistry, University of California, Los Angeles.

" Present address: Department of Chemistry, The College of Wooster, Wooster, OH 44691.

\# University of Southern Denmark, Odense University.

${ }^{\perp}$ The Institute for Cell Mimetic Space Exploration (CMISE) and Mechanical and Aerospace Engineering Department, University of California, Los Angeles.

$\S$ Veeco Instruments.

$¥$ California Institute of Technology.

(1) Molecular Nanoelectronics; M. A. Reed, T. L. Ed.; American Scientific Publishers: Stevenson Ranch, 2003.

(2) Gad-El-Hak, M. The MEMS Handbook; CRC Press: Boca Raton, 2001.

(3) Zhang, S. Mater. Today 2003, 6, 20-27.

(4) Hess, H.; Bachand, G. D.; Vogel, V. Chem. Eur. J. 2004, 10, 2110-2116.

10.1021/ja051088p CCC: $\$ 30.25$ @ 2005 American Chemical Society tromechanical systems (NEMS). The most current investigations have focused ${ }^{9}$ upon the transduction of chemical, electrical, or photochemical energy ${ }^{10}$ into controllable molecular motion and hold potential for producing controllable nano- and mesoscale mechanical systems driven by molecular machinery. ${ }^{11}$ A range of hybrid nanomechanical systems, based upon phenomena such as hydrogel swelling, ${ }^{12}$ the osmotic expansion of conjugated polymers, ${ }^{13}$ motions associated with molecular recognition in a supramolecular polymer system, ${ }^{14}$ ion intercalation in nano-

(5) (a) Soong, R. K.; Bachand, G. D.; Neves, H. P.; Olkhovets, A. G.; Montemagno C. D., Science 2000, 290, 1555-1558. (b) Liu, H.; Schmidt, J. J.; Bachand, G. D.; Rizk, S. S.; Looger, L. L.; Hellinga, H. W.; Montemagno, C. D. Nature Mater. 2002, 1, 173-177.

(6) Jiménez-Molero, M. C.; Dietrich-Buchecker, C.; Sauvage, J.-P. Chem. Commun. 2003, 1613-1616.

(7) Huang, T. J.; Brough, B.; Ho, C.-M.; Liu, Y.; Flood A, H.; Bonvallet, P.; Tseng, H.-R.; Baller, M.; Magonov, S.; Stoddart, J. F. Appl. Phys. Lett. 2004, 85, 5391-5393.

(8) (a) Yu, H. H.; Pullen, A. E.; Xu, B.; Swager, T. M. Polym. Mater. Sci. Eng. 2000, 83, 523-524. (b) Anquetil, P. A.; Yu, H. H.; Madden, J. D. Madden, P. G.; Swager, T. M.; Hunter, I. W. Proc. SPIE Int. Soc. Optical Eng. 2002, 4695, 424-434. (c) Anquetil, P. A.; Yu, H. H.; Madden, J. D. Swager, T. M.; Hunter, I. W. Proc. SPIE Int. Soc. Opt. Eng. 2003, 5051 , 42-53. (d) Yu, H. H.; Swager, T. M. IEEE J. Oceanic Eng. 2004, 29, 692-695.

J. AM. CHEM. SOC. 2005, 127, 9745-9759 — 9745 
particle films, ${ }^{15}$ surface stress changes resulting from DNA hybridization, ${ }^{16}$ and the electromechanical expansion of carbon nanotubes, ${ }^{17}$ have been successful in transferring molecular phenomena into macroscopic-scale motion. These systems, however, rely primarily upon the response of a bulk material, rather than upon individual molecular behavior. Recent advances in the molecular arena include a crown-annelated oligothiophene, ${ }^{18}$ a thiophene-fused [8] annulene, ${ }^{19}$ a unidirectional three-station [2] catenane, ${ }^{20}$ a series of unidirectional chiroptical rotary switches, ${ }^{21}$ ion-triggered contraction/extension molecular motions $^{22}$ and an array of rotaxane-based molecular switches and shuttles. ${ }^{9,23}$ Pioneering work in the development of linear

(9) For examples of chemically controllable molecular machines, see (a) Lane A. S.; Leigh, D. A.; Murphy, A. J. Am. Chem. Soc. 1997, 119, 1109211093. (b) Ashton, P. R.; Ballardini, R.; Balzani, V.; Baxter, I.; Credi, A. Fyfe, M. C. T.; Gandolfi, M. T.; Gómez-López, M.; Martínez-Díaz, M.V.; Piersanti, A.; Spencer, N.; Stoddart, J. F.; Venturi, M.; White, A. J. P. Williams, D. J. J. Am. Chem. Soc. 1998, 120, 11932-11942. (c) Lee, J. W.; Kim, K.; Kim, K. Chem. Commun. 2001, 1042-1043. (d) Elizarov, A. M.; Chiu, H.-S.; Stoddart, J. F. J. Org. Chem. 2002, 67, 9175-9181. (e) Badjic, J. D.; Balzani, V.; Credi, A.; Silvi, S.; Stoddart, J. F. Science 2004, 303, 1845-1849. (f) Kaiser, G.; Jarrosson, T.; Otto, S.; Ng, Y.-F.; Bond, A. D.; Sanders, J. K. M Angew. Chem., Int. Ed. 2004, 43, 19591962. (g) Liu, Y.; Flood, A. H.; Stoddart, J. F. J. Am. Chem. Soc. 2004 126, 9150-9151. For examples of electrochemically controllable molecular machines, see (h) Raehm, L.; Kern, J.-M.; Sauvage, J.-P. Chem. Eur. J. 1999, 5, 3310-3317. (i) Bermudez, V.; Capron, N.; Gase, T.; Gatti, F. G.; Kajzar, F.; Leigh, D. A.; Zerbetto, F.; Zhang, S. Nature 2000, 406, 608611. (j) Kern, J.-M.; Raehm, L.; Sauvage, J.-P.; Divisia-Blohorn, B.; Vidal, P.-L. Inorg. Chem. 2000, 39, 1555-1560. (k) Ballardini, R.; Balzani, V.; Dehaen, W.; Dell'Erba, A. E.; Raymo, F. M.; Stoddart, J. F.; Venturi, M. Eur. J. Org. Chem. 2000, 591-602. (1) Collin, J.-P.; Kern, J.-M.; Raehm, L.; Sauvage, J.-P. Molecular Switches; Feringa, B. L., Ed.; Wiley-VCH: Weinheim, 2000; pp 249-280. (m) Altieri, A.; Gatti, F. G.; Kay, E. R.; Leigh, D. A.; Paolucci, F.; Slawin, A. M. Z.; Wong, J. K. Y. J. Am. Chem Soc. 2003, 125, 8644-8654. (n) Poleschak, I.; Kern, J.-M.; Sauvage, J.-P. Chem. Commun. 2004, 474-476. For examples of optically controllable molecular machines, see: (o) Ballardini, R.; Balzani, V.; Gandolfi, M. T.; Prodi, L.; Venturi, M.; Philp, D.; Ricketts, H. G.; Stoddart, J. F. Angew. Chem., Int. Ed. Engl. 1993, 32, 1301-1303. (p) Ashton, P. R.; Ballardini, R.; Balzani, V.; Credi, A.; Dress, R.; Ishow, E.; Kocian, O.; Preece, J. A.; Spencer, N.; Stoddart, J. F.; Venturi, M.; Wenger, S. Chem. Eur. J. 2000 6, 3558-3574. (q) Brouwer, A. M.; Frochot, C.; Gatti, F. G.; Leigh, D. A.; Mottier, L.; Paolucci, F.; Roffia, S.; Wurpel, G. W. H. Science 2001 291, 2124-2128. (r) Collin, J.-P.; Laemmel, A.-C.; Sauvage, J.-P. New. J. Chem. 2001, 25, 22-24. (s) Bottari, G.; Leigh, D. A.; Pérez, E. M. J. Am. Chem. Soc. 2003, 125, 1360-13361. (t) Gatti, F. G.; Len, S.; Wong, J. K. Y.; Bottari, G.; Altieri, A.; Morales, M. A. F.; Teat, S. J.; Frochot, C.; Leigh, D. A.; Brouwer, A. M.; Zerbetto, F. Proc. Natl. Acad. Sci. U.S.A 2003, 100, 10-14. (u) Altieri, A.; Bottari, G.; Dehez, F.; Leigh, D. A. Wong, J. K. Y.; Zerbetto, F. Angew. Chem., Int. Ed. 2003, 42, 22962300. (v) Brouwer, A. M.; Fazio, S. M.; Frochot, C.; Gatti, F. G.; Leigh, D. A.; Wong, J. K. Y.; Wurpel, G. W. H. Pure Appl. Chem. 2003, 75, $1055-1060$

(10) (a) Chia, S.; Cao, J.; Stoddart, J. F.; Zink, J. I. Angew. Chem., Int. Ed. 2001, 40, 2447-2450. (b) Colasson, B. X.; Dietrich-Buchecker, C.; Jiménez-Molero, M. C.; Sauvage, J.-P. J. Phys. Org. Chem. 2002, 15, 476483. (c) Hernandez, R.; Tseng, H.-R.; Wong, J. W.; Stoddart, J. F.; Zink, J. J. Am. Chem. Soc. 2004, 126, 3370-3371. (d) Tseng, H.-R.; Wu, D.; Fang, N. X.; Zhang, X.; Stoddart, J. F. ChemPhysChem 2004, 5, 111116. (e) Huang, T. J.; Tseng, H.-R.; Sha, L.; Lu, W.; Brough, B.; Flood, A. H.; Yu, B.-D.; Celestre, P. C.; Chang, J. P.; Stoddart, J. F.; Ho, C.-M. Nano Lett. 2004, 4, 2065-2071.

(11) (a) Stoddart, J. F. Chem. Aust. 1992, 59, 576-577 and 581. (b) GómezLópez, M.; Preece, J. A.; Stoddart, J. F. Nanotechnology 1996, 7, 183192. (c) Balzani, V.; Gómez-López, M.; Stoddart, J. F. Acc. Chem. Res 1998, 31, 405-414. (d) Balzani, V.; Credi, A.; Raymo, F. M.; Stoddart, J. F. Angew. Chem., Int. Ed. 2000, 39, 3348-3391. (e) Harada, A. Acc. Chem Res. 2001, 34, 456-464. (f) Schalley, C. A.; Beizai, K.; Vögtle, F. Acc. Chem. Res. 2001, 34, 465-476. (g) Collin, J.-P.; Dietrich-Buchecker, C. Gaviña, P.; Jiménez-Molero, M. C.; Sauvage, J.-P. Acc. Chem. Res. 2001 34, 477-487. (h) Ballardini, R.; Balzani, V.; Credi, A.; Gandolfi, M. T.; Venturi, M. Struct. Bonding 2001, 99, 163-188. (i) Raehm, L.; Sauvage, J.-P. Struct. Bonding 2001, 99, 55-78. (j) Stainer, C. A.; Alderman, S. J.; Claridge, T. D. W.; Anderson, H. L. Angew. Chem., Int. Ed. 2002, 41 , 1769-1772. (k) Balzani, V.; Credi, A.; Venturi, M. Chem. Eur. J. 2002 8, 5524-5532. (1) Tseng, H.-R.; Stoddart, J. F. Modern Arene Chemistry; Astruc, D.; Wiley-VCH: Weinheim, 2002; pp 574-599. (m) Chen, Y.; Jung, G.-Y.; Ohlberg, D. A. A.; Li, X.; Stewart, D. R.; Jeppesen, J. O.; Nielsen, K. A.; Stoddart, J. F.; Williams, R. S. Nanotechnology 2003, 14 462-468. (n) Heath, J. R.; Ratner, M. A. Phys. Today 2003, May, 43-49. (o) Balzani, V.; Credi, A.; Venturi, M. Molecular Devices and Machines- $A$ Journey into the Nano World, Wiley-VCH: Weinheim, 2003. (p) Flood, A. H.; Ramirez, R. J. A.; Deng, W.-Q.; Muller, R. P.; Goddard III, W. A.; Stoddart, J. F. Aust. J. Chem. 2004, 57, 301-322. molecular muscles ${ }^{6,11 g, 24}$ has been investigated, based on compounds prepared using transition metal-based templates for the formation of two-component interlocked molecules in which the design is bioinspired to display contraction and extension movements. These molecular systems have been shown to undergo actuation, albeit in an incoherent manner in a solution environment, heralding their potential utilization ${ }^{6}$ in mechanical applications including nano- and microrobots for medicine and everyday-life pursuits. Although not insurmountable, the harnessing of molecular motion in a cooperative and coherent manner within an ordered mechanical setting is proving to be much more challenging. The alignment of liquid crystals has been effected ${ }^{25}$ over large distances by controllable chiroptical switches to achieve a range of colors. Although the bending of an AFM beam by photoisomerization of a polymer strand containing a single pendant azobenzene has been demonstrated ${ }^{26}$ successfully in a single-molecule optomechanical device, the actual deflection falls short of its theoretical maximum as a result of incomplete isomerization by the polymer. Thus, to our way of thinking, no single molecular system yet meets all of the stringent demands of processability, cooperativity, addressability, and efficiency required of NEMS.

(12) Juodkazis, S.; Mukai, N.; Wakaki, R.; Yamaguchi, A.; Matsuo, S.; Misawa H. Nature 2000, 408, 178-181.

(13) Bay, L.; West, K.; Sommer-Larsen, P.; Skaarup, S.; Benslimane, M. Adv Mater. 2003, 15, 310-313.

(14) (a) Schneider, H.-J.; Liu, T.; Lomadze, N. Angew. Chem., Int. Ed. 2003 , 42, 3544-3546. (b) Schneider, H.-J.; Liu, T.; Lomadze, N.; Palm, B. Adv Mater. 2004, 16, 613-615. (c) Schneider, H.-J.; Liu, T. Chem. Commun. 2004, 100-101.

(15) Raguse, B.; Muller, K. H.; Wieczorek, L. Adv. Mater. 2003, 15, 922926.

(16) Fritz, J.; Baller, M. K.; Lang, H. P.; Rothuizen, H.; Vettiger, P.; Meyer E.; Guntherodt, H. J.; Gerber, C.; Gimzewski, J. K. Science 2000, 288 316-318.

(17) Baughman, R. H ; Cui, C. X. Zakhidov, A A ; Iqbal, Z; Barisci, J. N. Spinks, G. M.; Wallace, G. G.; Mazzoldi, A.; De Rossi, D.; Rinzler, A. G.; Jaschinski, O.; Roth, S.; Kertesz, M. Science 1999, 284, 1340-1344.

(18) Jousselme, B.; Blanchard, P.; Levillain, E.; Delaunay, J.; Allain, M.; Richomme, P.; Rondeau, D.; Gallego-Planas, N.; Roncali, J. J. Am. Chem. Soc. 2003, 125, 1363-1370.

(19) Marsella, M. J.; Reid, R. J.; Estassi, S.; Wang, L. S. J. Am. Chem. Soc 2002, 124, 12507-12510

(20) Leigh, D. A.; Wong, J. K. Y.; Dehez, F.; Zerbetto, F. Nature 2003, 424 $174-179$.

(21) (a) Huck, N. P. M.; Jager, W. F.; de Lange, B.; Feringa, B. L. Science 1996, 273, 1686-1688. (b) Feringa, B. L.; van Delden, R. A.; Koumura, N.; Geertsema, E. M. Chem. Rev. 2000, 100, 1789-1816. (c) Feringa, B. L. Acc. Chem. Res. 2001, 34, 504-513. (d) Van Delden, R. A.; Koumura N.; Harada, N.; Feringa, B. L. Proc. Natl. Acad. Sci. U.S.A. 2002, 99, 49454949. (e) Komura, N.; Geertsema, E. M.; Van Gelder, M. B.; Meetsma, A.; Feringa, B. L. J. Am. Chem. Soc. 2002, 124, 5037-5051. (f) Van Delden, R. A.; Hurenkamp, J. H.; Feringa, B. L. Chem. Eur. J. 2003, 9 , 2845-2853.

(22) (a) Barboiu, M.; Lehn, J.-M. Proc. Natl. Acad. Sci. U.S.A. 2002, 99, 52015206. (b) Barboiu, M.; Vaughan, G.; Kyritsakas, N.; Lehn, J.-M. Chem Eur. J. 2003, 9, 763-769. (c) Kolomiets, E.; Berl, V.; Odriozola, I.; Stadler, A.-M.; Kyritsakas, N.; Lehn, J.-M. Chem. Commun. 2003, 23, 2868-2869. (d) Petitjean, A.; Khoury, R. G.; Kyritsakas, N.; Lehn, J.-M. J. Am. Chem Soc. 2004, 126, 6637-6647. (e) Barboiu, M.; Prodi, L.; Montalti, M.; Zaccheroni, N.; Kyritsakas, N.; Lehn, J.-M. Chem. Eur. J. 2004, 10, $2953-$ 2959.

(23) (a) Amabilino, D. B.; Ashton, P. R.; Boyd, S. E., Gómez-López, M.; Hayes, W.; Stoddart, J. F. J. Org. Chem. 1997, 62, 3062-3075. (b) Tseng, H.-R. Vignon, S. A.; Stoddart, J. F. Angew. Chem., Int. Ed. 2003, 42, 14911495. (c) Tseng, H.-R.; Vignon, S. A.; Celestre, P. C.; Perkins, J.; Jeppesen, J. O.; Fabio, A. D.; Ballardini, R.; Gandolfi, M. T.; Venturi, M.; Balzani, V.; Stoddart, J. F. Chem. Eur. J. 2004, 10, 155-172.

(24) (a) Blanco, M.-J.; Jiménez-Molero, M. C.; Chambron, J.-C.; Heitz, V.; Linke, M.; Sauvage, J.-P. Chem. Soc. Rev. 1999, 28, 293-305. (b) Jiménez, M. C.; Dietrich-Buchecker, C.; Sauvage, J.-P.; De Cian, A. Angew. Chem., Int Ed 2000, 39, 1295-1298. (c) Jiménez-Molero, M. C.; DietrichBuchecker, C.; Sauvage, J.-P. A. Angew. Chem., Int. Ed. 2000, 39, 32843287. (d) Jiménez-Molero, M. C.; Dietrich-Buchecker, C.; Sauvage, J.-P. Chem. Eur. J. 2002, 8, 1456-1466. (e) Dietrich-Buchecker, C.; JiménezMolero, M. C.; Sartor, V.; Sauvage, J.-P. Pure Appl. Chem. 2003, 75, $1383-$ 1393

(25) van Delden, R. A.; Koumura, N.; Harada, N.; Feringa, B. L., Proc. Natl. Acad. Sci. U.S.A. 2002, 99, 4945-4949. 
To date, the most complete and efficient forms of molecular machinery come, not from the laboratory, but from the biological world, e.g., the rotary motion of $\mathrm{F}_{0} \mathrm{~F}_{1}$-ATPase, which has been extensively investigated. ${ }^{5,27,28}$ In another example, the sarcomere, the cellular unit in the contraction of natural skeletal muscle, is composed primarily of alternately stacked filaments of the globular proteins actin and myosin..$^{29}$ During muscle contraction, the myosin and actin filaments slide relative to each other as the result of a powerful stroke within each of the many pendant myosin heads. ${ }^{30}$ This movement, which is reminiscent of a rowing action and is powered chemically through the hydrolysis of ATP, suggests that a biomimetic approach ${ }^{6,8}$ to the design of artificial molecular machinery may lie in the incorporation of linear, mutually sliding components that can undergo contraction and extension in response to a chemical stimulus.

In the realm of artificial molecular machinery, ${ }^{11}$ motormolecules, such as bistable catenanes and bistable rotaxanes, ${ }^{31}$ are particularly well-suited for nanomechanical work on account of their structural composition and ease of addressability. Most notable, however, is the fact that their mutually interlocked components can usually undergo controllable movements (Figure 1). The redox-active tetrathiafulvalene (TTF) unit serves ${ }^{32}$ as an excellent recognition site for the tetracationic cyclophane, cyclobis(paraquat-para-phenylene) $\left(\mathrm{CBPQT}^{4+}\right)$, as a result of electron donor and acceptor $(\pi-\pi$ stacking) interactions. In an unperturbed bistable [2] rotaxane, ${ }^{23 \mathrm{~b}}$ the $\mathrm{CBPQT}^{4+}$ ring possesses a dramatically greater affinity for the TTF unit than for the competing naphthalene (NP) ring system. Upon one- or twoelectron oxidation of the TTF unit, the $\mathrm{CBPQT}^{4+}$ ring is electrostatically repelled and moves immediately to the NP station. ${ }^{23 \mathrm{~b}, \mathrm{c}}$ The Coulombic repulsion of the $\mathrm{TTF}^{2+}$ unit, coupled with the $\pi$-donor ability of the NP station, provides a powerful "push-pull" mechanism for the translocation of the CBPQT ${ }^{4+}$ ring within the rotaxane's dumbbell component. Chemical or electrochemical reduction of the $\mathrm{TTF}^{2+}$ unit back to its neutral state allows the ring to return to its original thermodynamically

(26) Hugel, T.; Holland, N. B.; Cattani, A.; Moroder, L.; Seitz, M.; Gaub, H. Science 2002, 296, 1103-1106.

(27) (a) Boyer, P. D. Biochim. Biophys. Acta 1993, 1140, 215-250. (b) Boyer, P. D. J. Bio. Chem. 2002, 277, 39045-39061.

(28) (a) Noji, H.; Yasuda, R.; Yoshida, M.; Kinoshita, K. Nature 1997, 386 299-302. (b) Walker, J. E. Angew. Chem., Int. Ed. 1998, 37, 2308-2319. (c) Mehta, A. D.; Rief, M.; Spudich, J. A.; Smith, D. A.; Simmons, R. M. Science 1999, 283, 1689-1695. (d) Sambongi, Y.; Iko, Y.; Tanabe, M.; Omote, H.; Iwamoto-Kihara, A.; Ueda, I.; Yanagida, T.; Wada, Y.; Futai, M. Science 1999, 286, 1722-1724. (e) Braig, K.; Menz, R. I.; Montgomery, M. G.; Leslie, A. G.; Walker, J. E. Structure 2000, 8, 567-573. (f) Menz, R. I.; Walker, J. E.; Leslie, A. G. W. Cell 2001, 106, 331-341. (g) Imamura, H.; Nakano, M.; Noji, H.; Muneyuki, E.; Ohkuma, S.; Yoshida, M.; Yokoyama, K. Proc. Natl. Acad. Sci. U.S.A. 2003, 100, 2312-2315. (h) Itoh, H.; Takahashi, A.; Adachi, K.; Noji, H.; Yasuda, R.; Yoshida, M.; Kinosita, K. Nature 2004, 427, 465-468.

(29) Spudich, J. A.; Rock, R. S. Nature Cell Biol. 2002, 4, E8-E10.

(30) Geeves, M. A. Nature 2002, 415, 129-131.

(31) For a representative selection of monographs and reviews on catenanes and rotaxanes, see: (a) Schill, G. Catenanes, Rotaxanes and Knots; Academic: New York, 1971. (b) Amabilino, D. B.; Stoddart, J. F. Chem. Rev. 1995, 95, 2725-2828. (c) Vögtle, F.; Dunnwald, T.; Schmidt, T. Acc. Chem. Res. 1996, 29, 451-460. (d) Breault, G. A.; Hunter, C. A.; Mayers, P. C. Tetrahedron 1999, 55, 5265-5293. (e) Hubin, T. J.; Kolchinski, A G.; Vance, A. L.; Busch, D. H. Adv. Supramol. Chem. 1999, 5, 237-357. (f) Sauvage, J.-P.; Dietrich-Buchecker, C., Eds. Molecular Catenanes, Rotaxanes and Knots; VCH-Wiley: Weinheim, 1999. (g) Raehm, L. Hamilton, D. G.; Sanders, J. K. M. Synlett 2002, 1743-1761.

(32) (a) Philp, D.; Slawin, A. M. Z.; Spencer, N.; Stoddart, J. F.; Williams, D. J. Chem. Commun. 1991, 1584-1586. (b) Asakawa, M.; Ashton, P. R.; Balzani, V.; Credi, A.; Mattersteig, G.; Matthews, O. A.; Montalti, M.; Spencer, N.; Stoddart, J. F.; Venturi, M. Chem. Eur. J. 1997, 3, $1992-$ 1996. (c) Balzani, V.; Credi, A.; Mattersteig, G.; Matthews, O. A.; Raymo, F. M.; Stoddart, J. F.; Venturi, M.; White, A. J. P.; Williams, D. J. J. Org. Chem. 2000, 65, 1924-1936. (d) Nielsen, M. B.; Jeppesen, J. O.; Lau, J.; Lomholt, C.; Damgaard, D.; Jacobsen, J. P.; Becher, J.; Stoddart, J. F. J. Org. Chem. 2001, 66, 3559-3563.

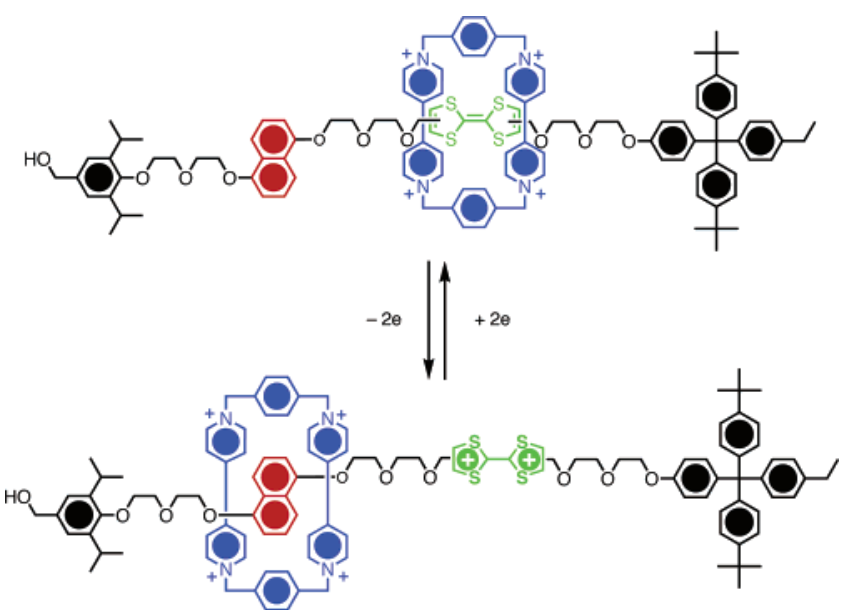

Figure 1. Structural formulas of the bistable [2]rotaxane motif that forms the basis for the design of a palindromic [3]rotaxane.

favored position ${ }^{23 b, c}$ by a thermally activated diffusive process. The bistable nature and the "all-or-nothing" switching behavior (i.e., only one of the translational isomers is significantly populated) of rotaxanes and catenanes have provided the basis for several molecular electronic devices. ${ }^{33}$ The switches, however, have yet to be harnessed in the mechanical sense for the performing of molecular-scale work. The mechanical sequence of "power stroke" and recovery step ${ }^{34}$ in rotaxane switching resembles the cooperative and progressive cycle of force production in natural biological machinery, thus inviting concept transfer ${ }^{35}$ from the life sciences into materials science during the design of a rotaxane-based molecular muscle.

Building upon knowledge gained ${ }^{23,36}$ in the design, synthesis, and operation of bistable [2]rotaxanes, a prototypical palindromic [3] rotaxane (molecular muscle) $\mathbf{P P R} \cdot 8 \mathbf{P F}_{6}$ was identified (Figure 2) in order to mimic the contraction and extension motion of skeletal muscles. This rational design incorporates two pairs of complementary TTF (green) and NP (red) recognition stations arranged symmetrically along a rod component which is encircled by two $\mathrm{CBPQT}^{4+}$ (blue) ring components. It was decided to introduce a rigid spacer between

(33) (a) Collier, C. P.; Mattersteig, G.; Wong, E. W.; Luo, Y.; Beverly, K.; Sampaio, J.; Raymo, F. M.; Stoddart, J. F.; Heath, J. R. Science 2000, 289, 1172-1175. (b) Pease, A. R.; Jeppesen, J. O.; Stoddart, J. F.; Luo, Y.; Collier, C. P.; Heath, J. R. Acc. Chem. Res. 2001, 34, 433-444. (c) Collier, C. P.; Jeppesen, J. O.; Luo, Y.; Perkins, J.; Wong, E. W.; Heath, J. R.; Stoddart, J. F. J. Am. Chem. Soc. 2001, 123, 12632-12641. (d) Luo, Y.; Collier, P.; Jeppesen, J. O.; Nielsen, K. A.; DeIonno, E.; Ho, G.; Perkins, J.; Tseng, H.-R.; Yamamoto, T.; Stoddart, J. F.; Heath, J. R. ChemPhysChem 2002, 3, 519-525. (e) Diehl, M. R.; Steuerman, D. W.; Tseng, H.-R.; Vignon, S. A.; Star, A.; Celestre, P. C.; Stoddart, J. F.; Heath, J. R. ChemPhysChem 2003, 4, 1335-1339. (f) Steuerman, D. W.; Tseng, H. R.; Peters, A. J.; Flood, A. H.; Jeppesen, J. O.; Nielsen, K. A.; Stoddart, J. F.; Heath, J. R. Angew. Chem., Int. Ed. 2004, 43, 6486-6491. (g) Flood, A. H.; Peters, A. J.; Vignon, S. A.; Steuerman, D. W.; Tseng, H.-R.; Kang, S.; Heath, J. R.; Stoddart, J. F. Chem. Eur. J. 2004, 10, 6558-6564. (h) Flood, A. H.; Stoddart, J. F.; Steuerman, D. W.; Heath, J. R. Science 2004 306, 2055-2056. (i) Mendes, P. M.; Flood, A. H.; Stoddart, J. F. Appl. Phys. A 2005, 80, 1197-1209.

(34) A power stroke is an activation-less process, and the results of ongoing studies are not able to distinguish between whether or not the electrostatically driven movement is barrier-less.

(35) Glink, P. T.; Stoddart, J. F. Pure Appl. Chem. 1998, 70, 419-424.

(36) (a) Bissell, R. A.; Córdova, E.; Kaifer, A. E.; Stoddart, J. F. Nature 1994 369, 133-137. (b) Jeppesen, J. O.; Perkins, J.; Becher, J.; Stoddart, J. F Angew. Chem., Int. Ed. 2001, 40, 1216-1221. (c) Jeppesen, J. O.; Nielsen, K. A.; Perkins, J.; Vignon, S. A.; Di Fabio, A.; Ballardini, R.; Gandolfi, M. T.; Venturi, M.; Balzani, V.; Becher, J.; Stoddart, J. F. Chem. Eur. J. 2003, 9, 2982-3007. (d) Yamamoto, T.; Tseng, H.-R.; Stoddart, J. F.; Balzani, V.; Credi, A.; Marchioni, F.; Venturi, M. Collect. Czech. Chem. Commun. 2003, 68, 1488-1514. (e) Kang, S.; Vignon, S. A.; Tseng, H.R.; Stoddart, J. F. Chem. Eur. J. 2004, 10, 2555-2564. 
a)
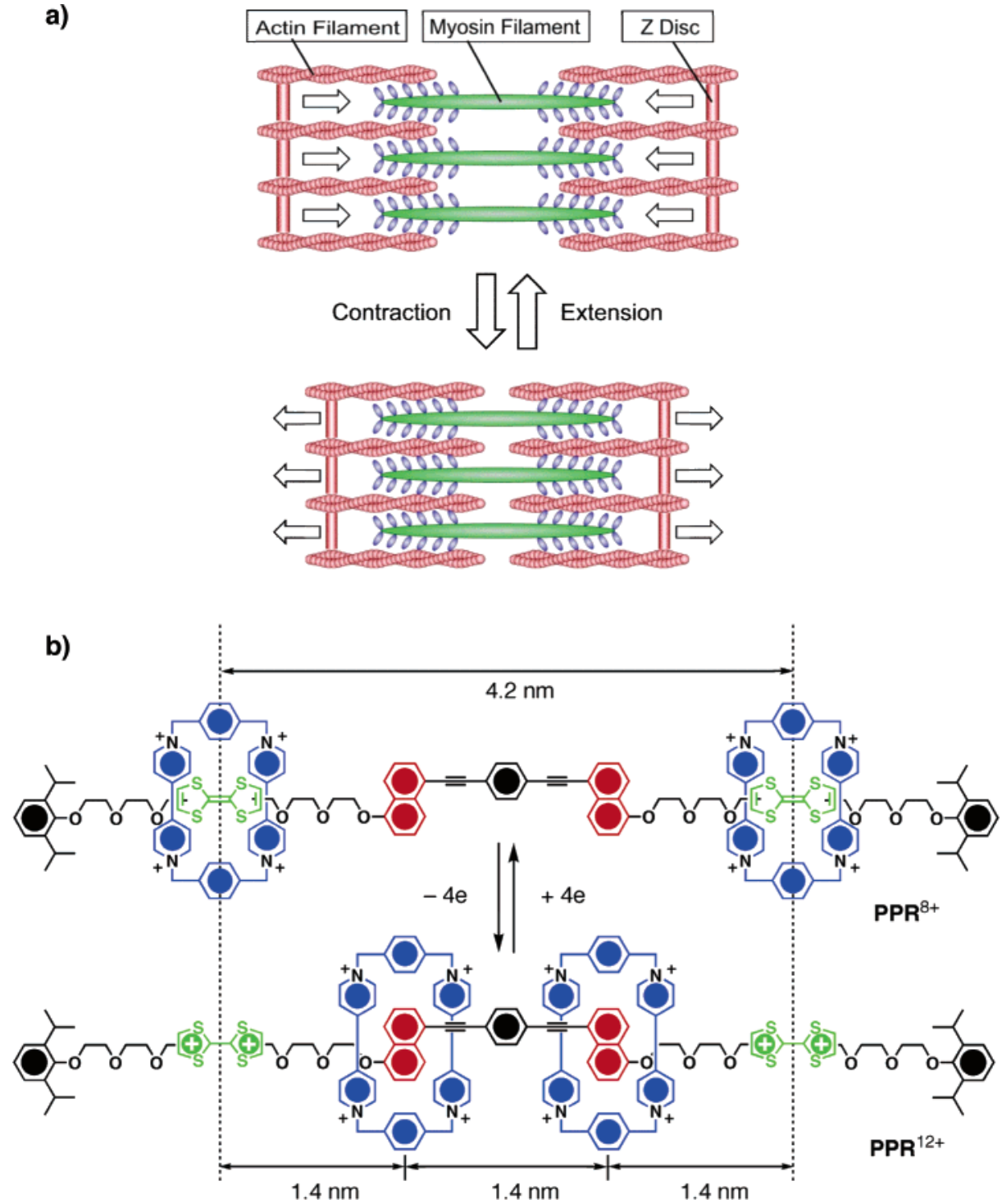

Figure 2. (a) Graphical representations of the constitution and cycle of contraction and extension of the sarcomeres that form basic element of movement in skeletal muscle. (b) Structural formulas of the contracted $\left(\mathbf{P P R}^{8+}\right)$ and the extended $\left(\mathbf{P P R}^{12+}\right)$ states of the prototypical molecular muscle. The distances between the adjacent recognition unit is around $1.4 \mathrm{~nm}$.

the two NP stations with a distance ${ }^{37}$ of about $1.4 \mathrm{~nm}$ as a compromise between the rigidity of the backbone, while retaining flexible di(ethylene glycol) chains for maintaining ${ }^{38}$ enhanced yields for the template-directed synthesis of the rotaxane. In common with the parent (Figure 1) two-station [2]rotaxanes, the location of the $\mathrm{CBPQT}^{4+}$ rings can be activated to switch between TTF stations and NP stations as a function of the TTF stations' redox state. Provided that the molecule is fully stretched, the distance between the $\mathrm{CBPQT}^{4+}$ rings can

(37) A fragment of $\mathbf{P P R}^{8+}$, constrained to its fully elongated conformation, was minimized with the AMBER* (Assisted Model Building and Energy Refinement) force field and GB/SA (Generalized Born/Surface Area) solvent model for $\mathrm{CHCl}_{3}$ as implemented in Maestro 3.0.038 module of the Schrödinger molecular modeling suite.

(38) The stabilizing $\mathrm{C}-\mathrm{H} \cdots \mathrm{O}$ interactions between the diethylene glycol oxygen atoms and the $\alpha$-bipyridinium hydrogen atoms greatly enhance the yield of the clipping reaction, see, for example, (a) Brown, C. L.; Philp, D.; Stoddart, J. F. Synlett 1991, 462-464. (b) Asakawa, M.; Dehaen, W. L'abbé, G.; Menzer, S.; Nouwen, J.; Raymo, F. M.; Stoddart, J. F.; Williams, D. J. J. Org. Chem. 1996, 61, 9591-9595. (c) Castro, R.; Nixo, K. R.; Evanseck, J. D.; Kaifer, A. E. J. Org. Chem. 1996, 61, 7298-7303. (d) Houk, K. N.; Menzer, S.; Newton, S. P.; Raymo, F. M.; Stoddart, J. F.; Williams, D. J. J. Am. Chem. Soc. 1999, 121, 1479-1487. (e) Raymo, F. M.; Bartberger, M. D.; Houk, K. N.; Stoddart, J. F. J. Am. Chem. Soc. 2001, 123, 9264-9267. be varied from between ca. 4.2 to ca. $1.4 \mathrm{~nm}$ apart. This interring distance change of ca. $2.8 \mathrm{~nm}$ represents a dramatic mechanical strain of $67 \%$. By contrast, a linear strain of $12 \%$ was recently reported for a conducting polymer actuator, ${ }^{13}$ and the maximum twitch sarcomere shortening in natural skeletal muscle is ${ }^{39}$ ca. $8 \%$. The [3] rotaxane TPR $8 \mathbf{P F}_{6}$ was designed (Figure 3) to incorporate a disulfide tether on each of the $\mathrm{CBPQT}^{4+}$ ring components. The introduction of the tethers provides an anchoring point by which the [3]rotaxane molecules can be attached to a gold surface, allowing the transduction of redox-driven mechanical movements of those molecules to impose strain on the underlying solid substrate. As the movable rings are Coulombically driven to different locations along the dumbbell, the strain generated by the molecular motions is expected to be transduced to the bound substrate.

In a recent communication, ${ }^{7}$ we described the operation of a NEMS device in which $\mathbf{T P R}^{8+}$ becomes self-assembled to the gold surface on an array of microcantilever beams of dimension

(39) Mutungi, G.; Ranatunga, K. W. J. Muscle Res. Cell Motil. 2000, 21, 565575 . 

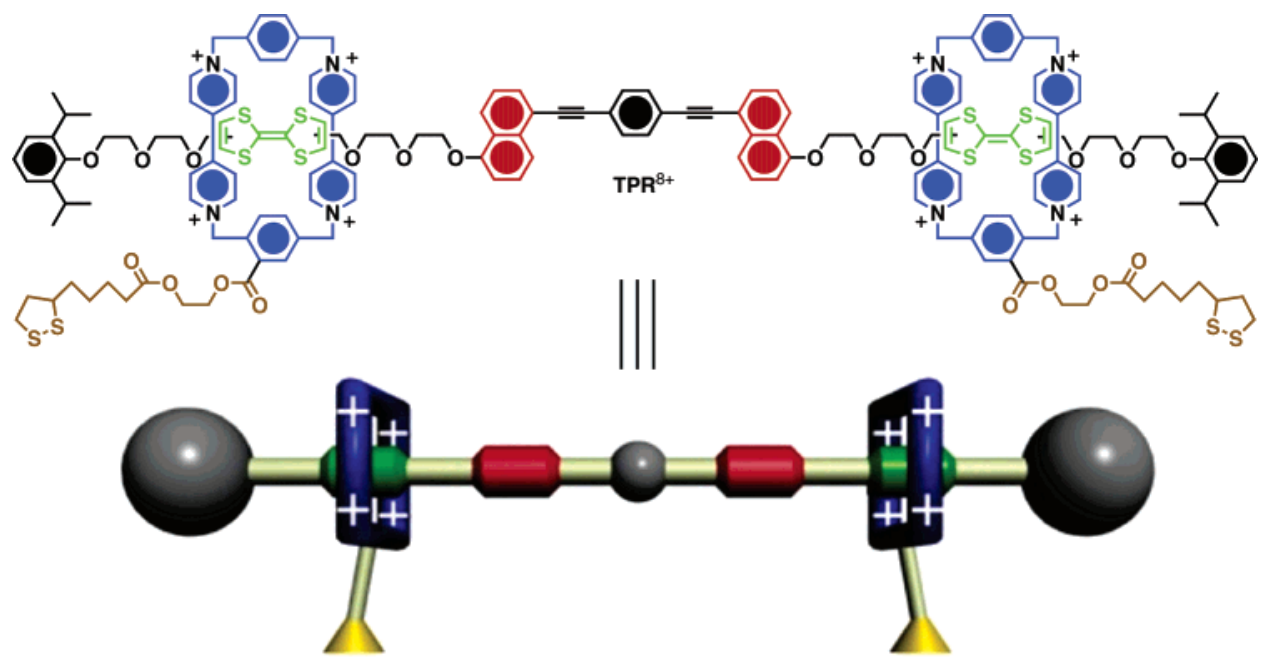

Figure 3. Structural formula and graphical representation of a disulfide-tethered molecular muscle $\mathbf{T P R}^{8+}$.

Scheme 1. Synthesis of the Dumbbell-Shaped Compounds 11 and TPD
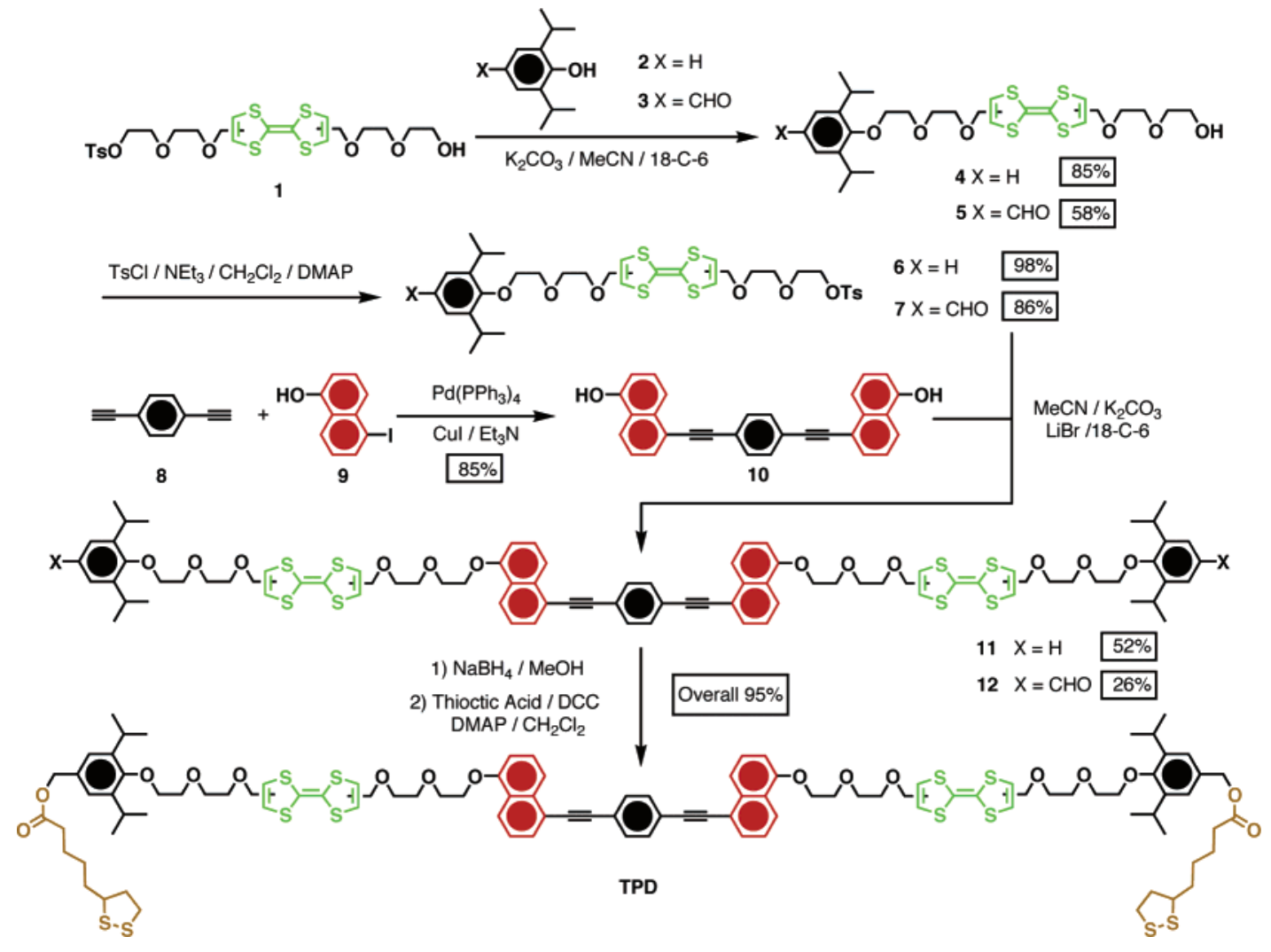

$500 \times 100 \times 1 \mu \mathrm{m}$ with a spring constant of $0.02 \mathrm{~N} \mathrm{~m}^{-1}$. Cantilever arrays were utilized on account of their design for optimal flexibility, which is one reason they are being utilized for sensors ${ }^{40 \mathrm{a}}$ and as microcalorimeters. ${ }^{40 \mathrm{~b}}$ The deflection of a cantilever is sensitive not only to temperature, $\mathrm{pH}$, electrostatic charges, and photothermal effects but also to chemical factors such as protein-ligand binding and DNA hybridization. ${ }^{16}$ In the latter example, control studies are critical for identifying the cause of the effect. In this context, we performed the

(40) (a) Baller, M. K.; Lang, H. P.; Fritz, J.; Gerber, C.; Gimzewski, J. K.; Drechsler, U.; Rothuizen, H.; Despont, M.; Vettiger, P.; Battiston, F. M.; Ramseyer, J. P.; Fornaro, P.; Meyer, E.; Guntherodt, H. J. Ultramicroscopy 2000, 82, 1-9. (b) Berger, R.; Gerber, C.; Gimzewski, J. K.; Meyer, E.; Guntherodt, H. J. Appl. Phys. Lett. 1996, 69, 40-42. necessary control studies that verify the active role that the flexing of the molecular muscle plays in bending the cantilever beams.

In this full paper, we describe (i) the synthesis (Scheme 1) of a prototypical palindromic molecular muscle PPR $8 \mathbf{P F}_{6}$, a disulfide-tethered molecular muscle $\mathbf{T P R} \cdot 8 \mathrm{PF}_{6}$, and a control dumbbell-shaped component TPD and (ii) the spectroscopic characterization of the redox-controllable biomimetic contraction-extension mechanical movement of the molecular muscles in solution, with respect to chemical or electrochemical stimulus. Finally, we return to the mechanism of force production in the molecular muscles and consider the details of how the chemomechanical transduction of nanometer movements causes a micron-scale cantilever to bend controllably. 
Scheme 2. Synthesis of the Prototype Palindromic [3]Rotaxane PPR $8 \mathrm{PF}_{6}$ and a [2]Rotaxane 15.4PF 6

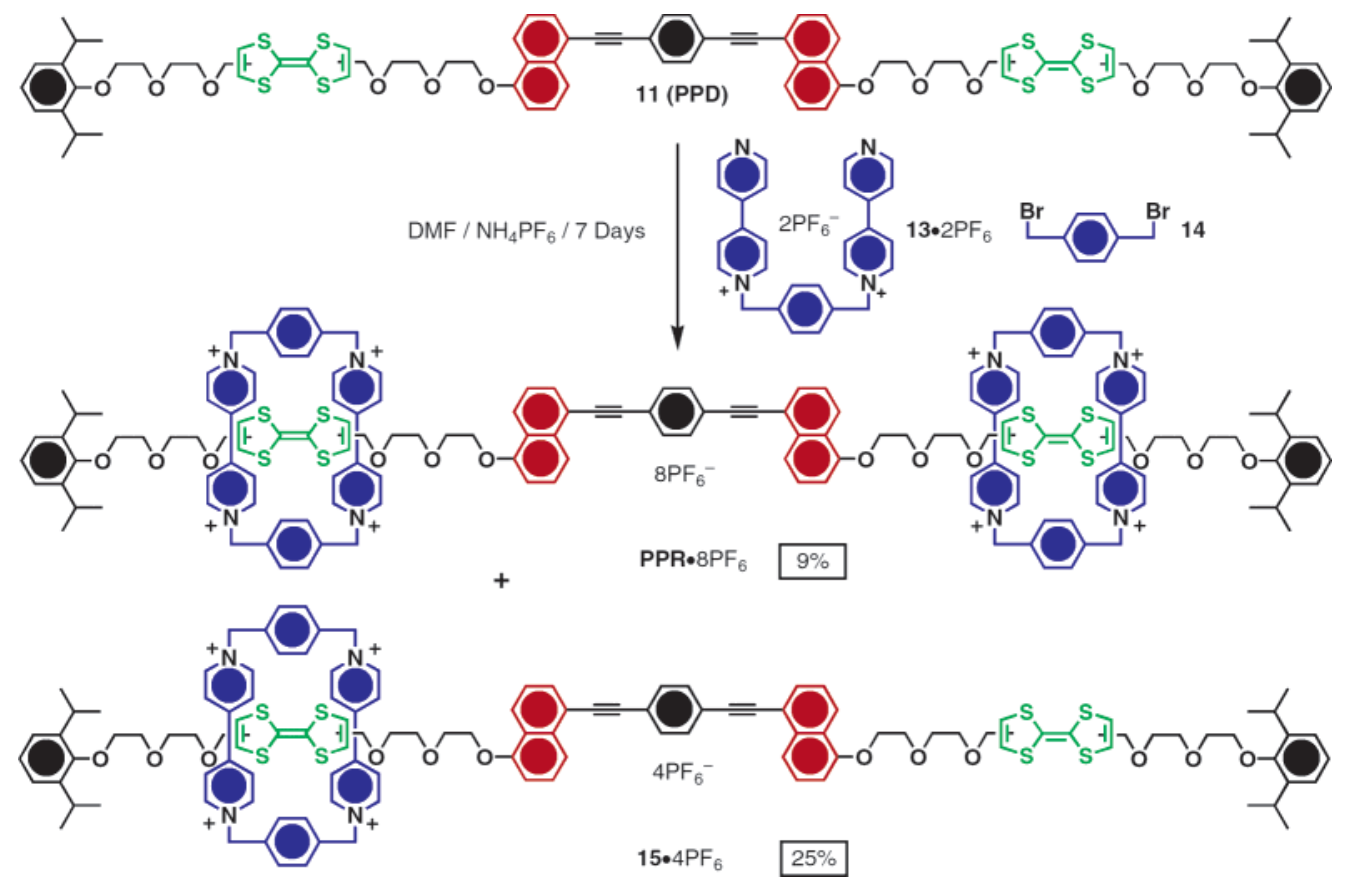

\section{Results and Discussion}

Synthesis. The routes employed in the synthesis of the [3]rotaxanes PPR $8 \mathrm{PF}_{6}$ and $\mathbf{T P R} \cdot 8 \mathrm{PF}_{6}$, and the control dumbbellshaped compound TPD are outlined in Schemes 1-3. Reaction (Scheme 1) of the TTF-containing tosylate 1 and 2,6-diisopropylphenol (2) or 4-hydroxy-3,5-diisopropyl-benzaldehyde $(3)^{41}$ in the presence of $\mathrm{K}_{2} \mathrm{CO}_{3}$ afforded, respectively, the alcohols 4 and $\mathbf{5}$, which were tosylated subsequently to give $\mathbf{6}$ and $\mathbf{7}$. The synthesis of the rigid dinaphthol $\mathbf{1 0}$ was achieved by a Sonogashira coupling ${ }^{42}$ between 1,4-diacetylenebenzene $(\mathbf{8})$ and the iodide ${ }^{43} \mathbf{9}$ in $85 \%$ yield. Reaction of the dinaphthol $\mathbf{1 0}$ and 2.2 equiv of the tosylate 6 or 7 in the presence of $\mathrm{K}_{2} \mathrm{CO}_{3}$ afforded the dumbbell-shaped compound 11 (PPD) or 12. The dialdehyde 12 was further reduced to a diol, followed by its esterification (DCC/DMAP/ $\mathrm{CH}_{2} \mathrm{Cl}_{2}$ ) with thioctic acid, to give the disulfide-tethered dumbbell-shaped compound TPD. The prototypical palindromic [3] rotaxane $\mathbf{P P R} \cdot 8 \mathrm{PF}_{6}$ and a [2]rotaxane $\mathbf{1 5} \cdot 4 \mathrm{PF}_{6}$ were separated (Scheme 2) after stirring a mixture of PPD, the bis(hexafluorophosphate) salt ${ }^{44} 13 \cdot 2 \mathrm{PF}_{6}$, 1,4-bis(bromomethyl)benzene (14) and $\mathrm{NH}_{4} \mathrm{PF}_{6}$ in DMF under ambient conditions, followed by preparative thin-layer chromatography (PTLC) on $\mathrm{SiO}_{2}$ using $\mathrm{Me}_{2} \mathrm{CO} / \mathrm{NH}_{4} \mathrm{PF}_{6}\left(1.0 \mathrm{~g} \mathrm{NH}_{4}-\right.$ $\mathrm{PF}_{6}$ in $100 \mathrm{~mL} \mathrm{Me} 2 \mathrm{CO}$ ) as the eluent.

Scheme 3 outlines the preparation of the active disulfidetethered [3] rotaxane $\mathbf{T P R} \cdot 8 \mathrm{PF}_{6}$. The dibromide ${ }^{45} \mathbf{1 6}$ underwent esterification (DCC/DMAP/ $\mathrm{CH}_{2} \mathrm{Cl}_{2}$ ) with ethylene glycol (17) to give the alcohol $\mathbf{1 8}$ in $33 \%$ yield. Refluxing a mixture of $\mathbf{1 8}$ and 4,4'-bipyridine (19) in $\mathrm{MeCN}$ afforded the dicationic salt 20. $2 \mathrm{PF}_{6}$, after counterion exchange $\left(\mathrm{NH}_{4} \mathrm{PF}_{6} / \mathrm{H}_{2} \mathrm{O}\right)$. Compound $22 \cdot 2 \mathrm{PF}_{6}$ was obtained in a yield of $98 \%$ by esterification of $\mathbf{2 0} 2 \mathrm{PF}_{6}$ with thioctic acid (21). The active disulfide-tethered

(41) Roth, B.; Baccanari, D. P.; Sigel, C. W.; Hubbell, J. P.; Eaddy, J.; Kao, J. C.; Grace, M. E.; Rauckman, B. S. J. Med. Chem. 1988, 31, 122-129.

(42) Taylor, R. J. K., Ed. Organocopper Reagents; IRL Press: Oxford, 1994.

(43) Ishii, H., Harada, Y.; Asaka, T.; Murakami, Y.; Honaoka, T.; Ikeda, N. Yakugaku Zasshi 1976, 96, 1259-1264.

(44) Stoddart, J. F. et al. J. Am. Chem. Soc. 1992, 114, 193-218.

(45) Stoddart, J. F. et al. Chem. Eur. J. 1997, 3, 152-169. [3]rotaxane TPR $\cdot 8 \mathrm{PF}_{6}$ was prepared, after stirring a mixture of PPD, the disulfide-containing bis(hexafluorophosphate) salt 22. $2 \mathrm{PF}_{6}, 1,4$-bis(bromomethyl)benzene (14), and $\mathrm{NH}_{4} \mathrm{PF}_{6}$ in DMF for 7 days. Ultrahigh-pressure conditions (12 kbar) were employed in order to increase the yield of the [3] rotaxane. The [3] rotaxane TPR$\cdot 8 \mathrm{PF}_{6}$ and [2] rotaxane $\mathbf{2 3} \cdot 4 \mathrm{PF}_{6}$ were separated by column chromatography on $\mathrm{SiO}_{2}$ and isolated as green solids in yields of $10 \%$ and $14 \%$, respectively.

Structural Characterization of [3]- and [2]Rotaxanes by ${ }^{1} \mathbf{H}$ NMR Spectroscopy and Mass Spectrometry. The ${ }^{1} \mathrm{H}$ NMR spectrum $\left(\mathrm{CD}_{3} \mathrm{COCD}_{3} / 298 \mathrm{~K}\right)$ of the [3] rotaxane PPR $8 \mathrm{PF}_{6}$ revealed (Figure $4 \mathrm{a}$ ) two pairs of signals of equal intensities at $\delta=6.25$ and $6.30 \mathrm{ppm}$, and at $\delta=6.33$ and $6.38 \mathrm{ppm}$, respectively, which correspond to the TTF protons in the units, cis- and trans-isomers. ${ }^{23 \mathrm{~b}}$ A 1:2 integration ratio between the signals of the dumbbell and the $\mathrm{CBPQT}^{4+}$ ring indicates that, for each dumbbell component, there are two encircling CB$\mathrm{PQT}^{4+}$ rings in keeping with the molecular structure of a [3]rotaxane. For the [2] rotaxane $15 \cdot 4 \mathrm{PF}_{6}$, integration between the dumbbell signals and the $\mathrm{CBPQT}^{4+}$ signals gives a ratio of $1: 1$, indicating that only one ring encircles the dumbbell component. In both cases, no resonances - that could be ascribed to encircled NP ring protons-were observed, clearly suggesting close to an "all-or-nothing" equilibrium. Electrospray ionization mass spectrometry (ESI-MS) unambiguously distinguishes the [3] rotaxanes from the corresponding [2]rotaxanes. The mass spectrum of [3] rotaxane $\mathbf{P P R} \cdot 8 \mathrm{PF}_{6}$ reveals $^{46}$ (Table 1) a singly charged peak at $m / z$ values $1742.4\left(\left[M-2 \mathrm{PF}_{6}\right]^{2+}\right)$, together with doubly and triply charged peaks at $m / z$ values $1113.3\left(\left[M-3 \mathrm{PF}_{6}\right]^{3+}\right)$ and $798.7\left(\left[M-4 \mathrm{PF}_{6}\right]^{4+}\right)$, an observation which corresponds to the consecutive loss of two, three and four hexafluorophosphate ions (mol. wt. $=145$ Da each), and a molecular mass of 3774.8. In comparison, the mass spectrum of the [2] rotaxane 15.4PF 6 reveals peaks at $m / z$ values $1192.4,746.6$ and 523.7, corresponding to the mass of $\left[M-2 \mathrm{PF}_{6}\right]^{2+},\left[M-3 \mathrm{PF}_{6}\right]^{3+}$ and

(46) Molecular weight and $\mathrm{m} / \mathrm{z}$ values apply to the lowest mass component of any isotope distribution and are based on a scale in which ${ }^{12} \mathrm{C}=12.000$. 
Scheme 3. Synthesis of a Disulfide-Tethered [3]Rotaxane TPR $8 \mathrm{PF}_{6}$ and a [2]Rotaxane 23.4PF 6

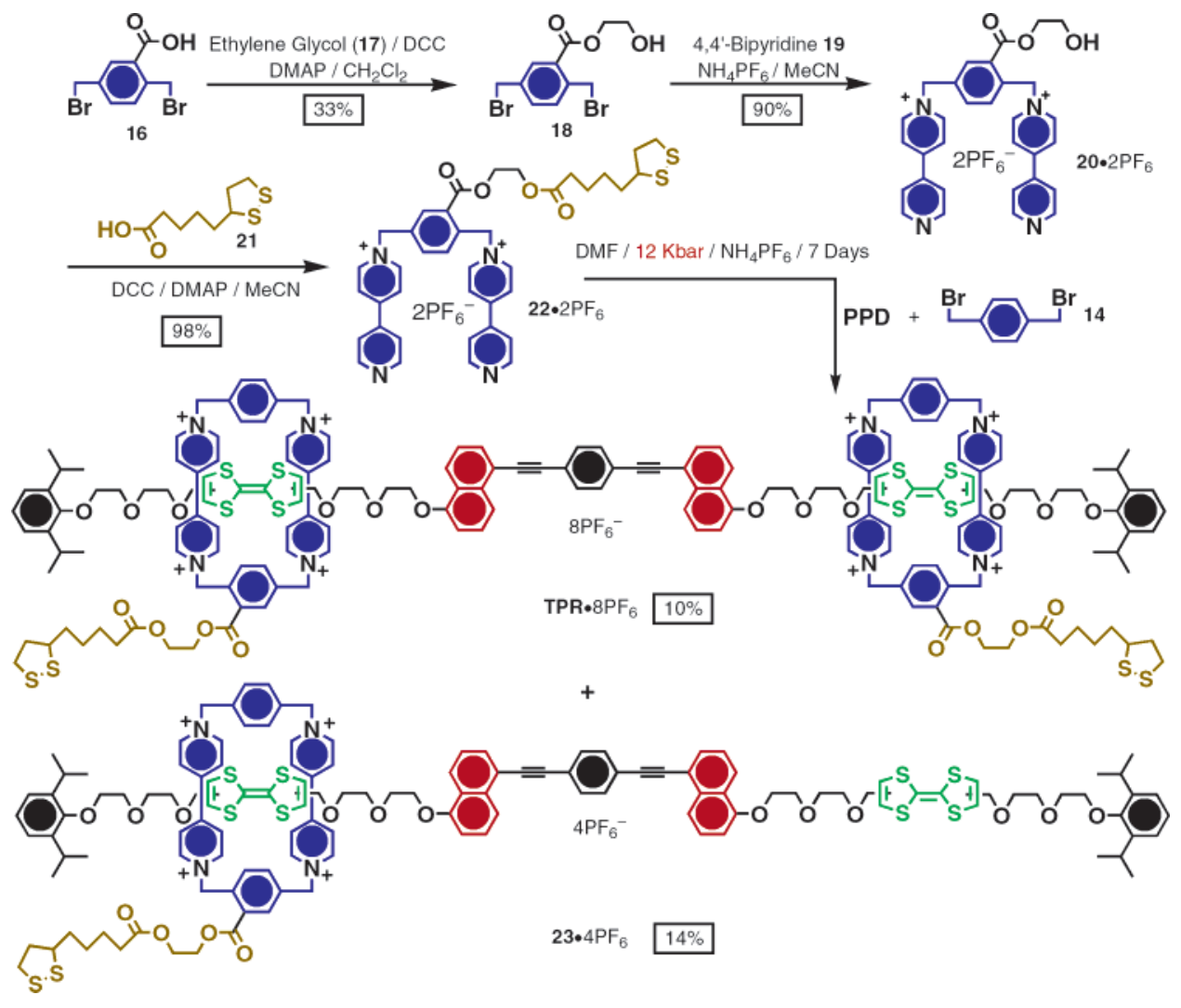

$\left[M-4 \mathrm{PF}_{6}\right]^{4+}(M=2674.8)$. The mass difference between the two compounds is 1100.0 , corresponding to the mass of one $\mathrm{CBPQT}^{4+}$ ring component. Similarly, the mass spectra of the active disulfide-tethered [3] rotaxane TPR $8 \mathbf{P F}_{6}$ and [2] rotaxane 23. $4 \mathrm{PF}_{6}$ reveal (Table 1) the consecutive loss of up to five hexafluorophosphate ions and a mass difference of one disulfidetethered $\mathrm{CBPQT}^{4+}$ ring component between their molecular weights.

Chemical Switching of the Palindromic [3]Rotaxane Monitored by ${ }^{1} \mathbf{H}$ NMR Spectroscopy. A series of ${ }^{1} \mathrm{H}$ NMR spectroscopic experiments were performed to reveal the precise nature $^{23 \mathrm{~b}}$ of the redox-controllable switching process undergone by the [3] rotaxane $\mathbf{P P R} \cdot 8 \mathbf{P F}_{6}$. After recording the spectrum (Figure $4 \mathrm{a}$ ) of a solution of $\mathbf{P P R} \cdot 8 \mathrm{PF}_{6}$ in $\mathrm{CD}_{3} \mathrm{COCD}_{3}$ at 233 $\mathrm{K}, 4.6$ equiv of the one-electron oxidant, tri( $p$-bromophenyl)amminium hexafluoroantimonate, was added and the sample was cooled back down immediately ${ }^{47}$ to $233 \mathrm{~K}$. Examination of the spectrum (Figure 4b) for the oxidized sample provides evidence for complete oxidation of both TTF units to their bisoxidized forms, i.e., $\mathbf{P} \mathbf{P R}{ }^{8+}$ is oxidized to $\mathbf{P} \mathbf{P R}{ }^{12+}$. The two peaks, corresponding to the dicationic $\mathrm{TTF}^{2+}$ units, can be identified at $\delta=9.42$ and $9.41 \mathrm{ppm}$. As a result of the deshielding effect of these aromatic units, the signals corresponding to the adjacent $\mathrm{CH}_{2}$ groups are moved downfield away from the $\mathrm{CH}_{2} \mathrm{O}$ signals and can be observed at $\delta=5.38$ and $5.34 \mathrm{ppm}$. Evidence for movement of the $\mathrm{CBPQT}^{4+}$ rings from the TTF unit to the NP ring systems is apparent from the observation of upfield shifts of the peaks corresponding to the protons of the NP stations. Dramatically, the H-4/8 protons of the encircled NP sites-which participate in $\mathrm{C}-\mathrm{H} \cdots \pi$ interac-

(47) It is necessary to keep the sample at low temperature to increase the stability over the time period necessary to collect the $2 \mathrm{D}$ spectra. tions with the para-phenylene bridges in the $\mathrm{CBPQT}^{4+}$ ringresonate upfield (Figure 5) at $\delta=2.95$ and $2.88 \mathrm{ppm}$. Other peaks, corresponding to NP protons, resonate (Figures 4 and 5) at $\delta=7.39,6.41,6.35$, and 6.02. Examination of the ${ }^{1} \mathrm{H} \mathrm{DQF}-$ COSY (double quantum filtered correlation spectroscopy) spectrum for the oxidized [3] rotaxane shows clearly the scalar coupling between the protons of the NP stations. Addition of $\mathrm{Zn}$ powder to the $\mathrm{CD}_{3} \mathrm{COCD}_{3}$ solution, followed by vigorous shaking, leads to reduction of the $\mathrm{TTF}^{2+}$ dications back to their neutral state and the consequent shuttling back of the $\mathrm{CBPQT}^{4+}$ rings from the NP stations to the TTF ones. The original ${ }^{1} \mathrm{H}$ NMR spectrum is restored (Figure 4c) in all its glory!

Electrochemical Switching Monitored by CV and UV/Vis Spectroelectrochemistry. The redox-controlled contraction and extension of the inter-ring distance in the bistable [3] rotaxane $\mathbf{P P R}^{8+}$ has been investigated using cyclic voltammetry (CV) and UV-visible spectroelectrochemistry. In the presence of two mechanically mobile $\mathrm{CBPQT}^{4+}$ rings, it is important to understand how the mechanism of electromechanical switching is coupled to the sequence of TTF-based oxidations. In particular, do the two $\mathrm{CBPQT}^{4+}$ rings move in a stepwise or in concerted manner? To answer this question, CVs were recorded at different scan rates and at two temperatures - room temperature and -25 ${ }^{\circ} \mathrm{C}$-in order to time-resolve the mechanical switching. In addition, slow scan-rate $\mathrm{CV}$, in conjunction with controlledpotential UV-visible spectroelectrochemistry, was employed ${ }^{48}$ to detect any changes in the switching mechanism that occur at slow switching speeds. The bistable [2] rotaxane $15^{4+}$ was $^{48}$ investigated in order to identify whether the presence of an additional unpopulated station influences its switching perfor-

(48) Liu, Y.; Flood, A. H.; Moscowitz, R. M.; Stoddart, J. F. Chem. Eur. J. 2004, 10, 369-385 


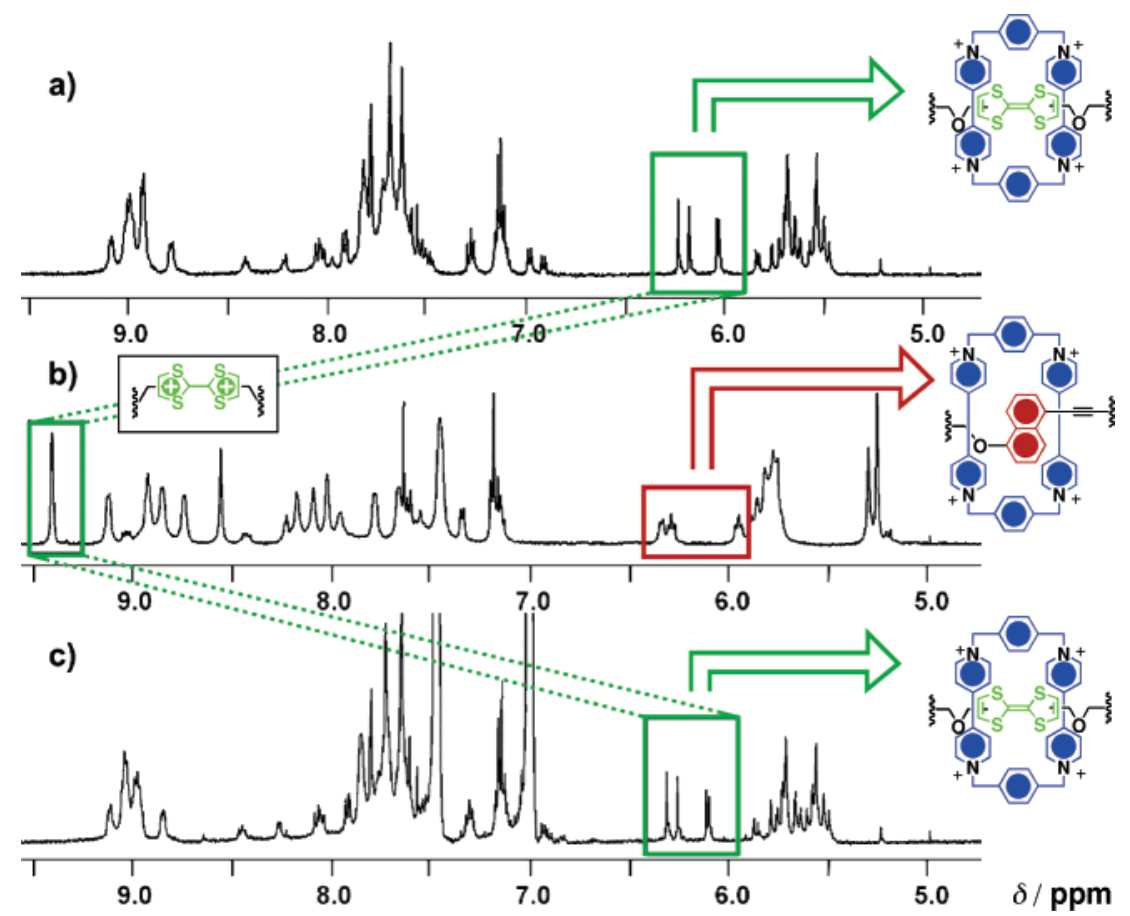

Figure 4. ${ }^{1} \mathrm{H}$ NMR spectra of (a) $\mathbf{P P R}^{8+}$ at room temperature, (b) bis-oxidized $\mathbf{P P R}{ }^{12+}$ at $243 \mathrm{~K}$, and (c) reduced $\mathbf{P P R}^{8+}$ at room temperature. All spectra were recorded in $\mathrm{CD}_{3} \mathrm{COCD}_{3}$ at $500 \mathrm{MHz}$. The green box highlights peaks from TTF protons and the red box indicates peaks of three of the "inside" NP protons.

Table 1. The ESI-MS Characterization ${ }^{a}$ of [2]- and [3]Rotaxanes

\begin{tabular}{|c|c|c|c|c|}
\hline $\begin{array}{c}\text { no. of } \\
\text { lost } \mathrm{PF}_{6}^{-} \\
\text {counterions }\end{array}$ & $\begin{array}{c}\text { PPR } 88^{2} F_{6} \\
M W=3774.8\end{array}$ & $\begin{array}{c}15 \cdot 4 \mathrm{PF}_{6} \\
\mathrm{MW}=2674.8\end{array}$ & $\begin{array}{c}\operatorname{TPR}^{8} 8 \mathrm{PF}_{6} \\
\mathrm{MW}=4326.8\end{array}$ & $\begin{array}{c}23 \cdot 4 \mathrm{PF}_{6} \\
\mathrm{MW}=2950.6\end{array}$ \\
\hline 2 & $1742.4(18 \%)$ & $1192.4(32 \%)$ & $2018.4(55 \%)$ & $1330.3(30 \%)$ \\
\hline 3 & $1113.3(100 \%)$ & $746.6(97 \%)$ & $1297.3(87 \%)$ & $838.6(100 \%)$ \\
\hline 4 & $798.7(16 \%)$ & $523.7(100 \%)$ & $936.8(100 \%)$ & $592.7(21 \%)$ \\
\hline 5 & - & - & $720.4(22 \%)$ & - \\
\hline
\end{tabular}

${ }^{a}$ Data are presented as $\mathrm{m} / \mathrm{z}$ ratio and (relative abundance). Molecular weight and $\mathrm{m} / \mathrm{z}$ values apply to the lowest mass component of any isotope distribution and are based on a scale in which ${ }^{12} \mathrm{C}=12.000$.

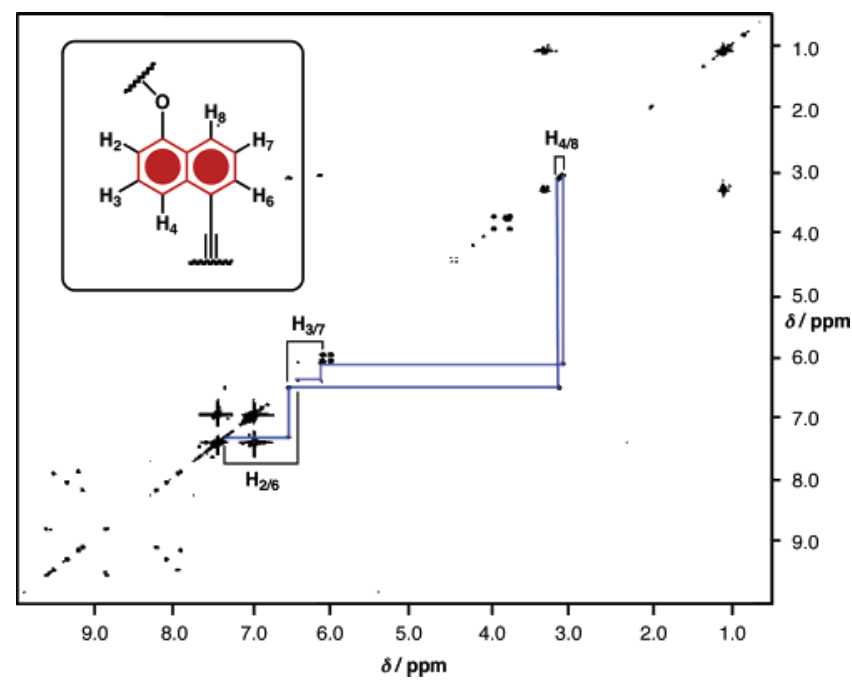

Figure 5. 2D DQF-COSY of the bis-oxidized $\mathbf{P P R}^{12+}$, showing the correlation between the NP proton resonances. The H4/8 protons of NP ring system resonate at very high field $\delta=3.20$ and $3.15 \mathrm{ppm}$, indicating the location of the NP ring system inside the $\mathrm{CBPQT}^{4+}$ macrocycle.

mance or if it behaves, somewhat trivially, as a linear combination of the dumbbell-like moiety plus that of the [2]rotaxanelike other half. For both rotaxanes, the dumbbell compound
PPD, as well as a disubstituted diethylene glycol TTF compound (TTF thread) and the $\mathrm{CBPQT}^{4+}$ cyclophane were utilized as mechanically inactive control systems.

The redox-mediated mechanical switching of $\mathbf{P P R}{ }^{8+}$ and the corresponding dumbbell PPD were characterized using CV (Figure 6) at fast scan rates. The oxidative region of the $\mathrm{CV}$ of PPR $^{8+}$ displays (Figure 6a) a single anodic peak at $+800 \mathrm{mV}$ and two cathodic reduction peaks at +700 and $+400 \mathrm{mV}$. This $\mathrm{CV}$ profile is qualitatively similar to those that have been obtained for bistable [2] catenanes and [2]rotaxanes. ${ }^{32 c, 49}$ Consequently, the first process can be assigned to the formation of the two $\mathrm{TTF}^{2+}$ dications, concomitant with the mechanical movements of the $\mathrm{CBPQT}^{4+}$ rings to the two NP ring systems. The cathodic peaks on the return sweep can be assigned to the stepwise reductions of the dications to the monocations $\mathrm{TTF}^{+}$• and subsequently the neutral TTF. By contrast, the dumbbell component PPD displays (Figure 6d) two well-separated processes, corresponding to the oxidations of both TTF units at the same potentials. The TTF-based oxidation processes lie at $E_{1 / 2}(\mathbf{P P D})^{2+/ 0}=+350 \mathrm{mV}$ and $E_{1 / 2}(\mathbf{P P D})^{4+/ 2+}=+800 \mathrm{mV}$, respectively, and the two-electron oxidation product is more stable in $\mathrm{CH}_{2} \mathrm{Cl}_{2}$ than in $\mathrm{MeCN}$ by comparison with the $\mathrm{CV}$ of the TTF thread. The reduction region of the $\mathrm{CV}$ of $\mathbf{P P R}{ }^{8+}$ displays two processes with cathodic peaks at approximately -400 and $-800 \mathrm{mV}$. Each redox process can be assigned by analogy (Figure 6c) to the free $\mathrm{CBPQT}^{4+}$ cyclophane. Consequently, the first process corresponds ${ }^{32 c}$ to the reduction of the two $\mathrm{CBPQT}^{4+}$ rings, and expresses itself in two closely spaced peaks. The first is revealed as a weak shoulder at $-355 \mathrm{mV}$, occurring at the same potential as that $(-357 \mathrm{mV})$ of the free cyclophane while the second process is shifted by $100 \mathrm{mV}$ to more negative potentials $(-452 \mathrm{mV})$. The splitting has previ-

(49) Flood, A. H.; Peters, A. J.; Vignon, S. A.; Steuerman, D. W.; Tseng, H.R.; Kang, S.; Heath, J. R.; Stoddart, J. F., Chem. Eur. J. 2004, 24, 65586561 . 


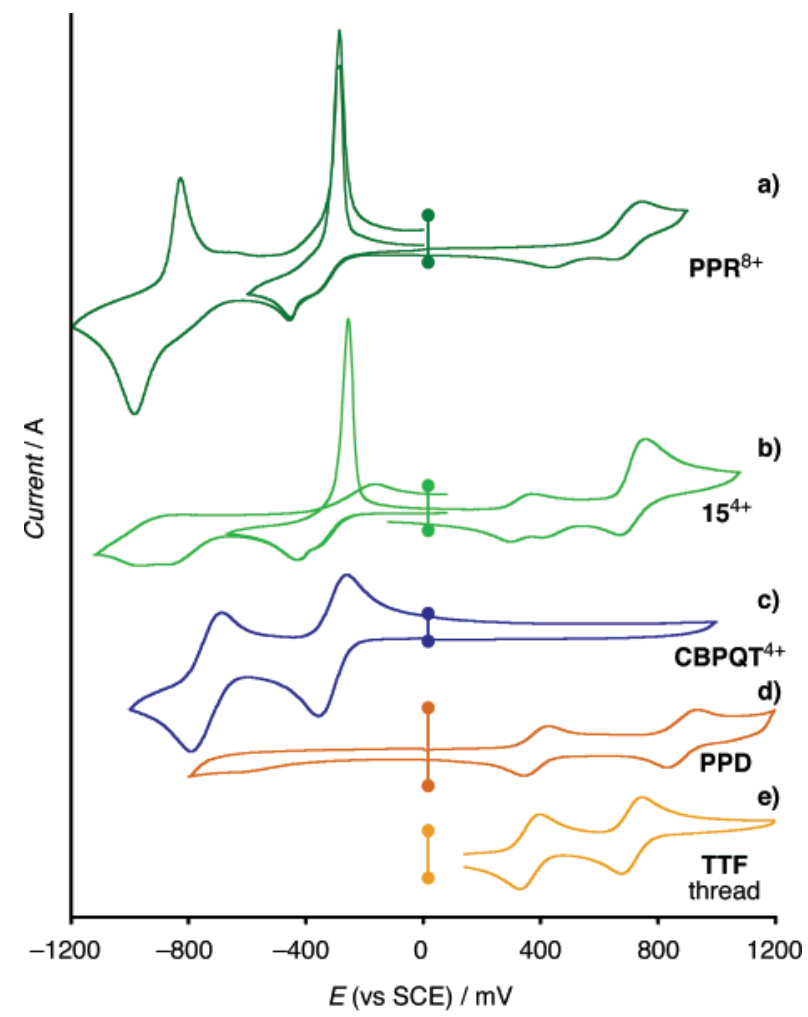

Figure 6. Cyclic voltammetry of the (a) molecular muscle $\mathbf{P P R}{ }^{8+}$, and its precursor compounds in the form of (b) [2]rotaxane $\mathbf{1 5}^{4+}$, (c) $\mathrm{CBPQT}^{4+}$, (d) PPD, and (e) the TTF thread. The data have been scaled for ease of comparison of the CVs and the scale bars at $0.0 \mathrm{~V}$ correspond to $5 \mu \mathrm{A}$. All data presented was recorded at $200 \mathrm{mV} \mathrm{s}^{-1}$ in argon purged $\mathrm{MeCN}$ except for PPD $\left(\mathrm{CH}_{2} \mathrm{Cl}_{2}\right), 1.0-0.5 \times 10^{-3} \mathrm{~mol} \mathrm{~L}^{-1}, 0.1 \mathrm{M} \mathrm{TBAPF}_{6}$, room temperature, glassy carbon working electrode $\left(0.0178 \mathrm{~cm}^{2}\right)$.

ously been taken ${ }^{44,50}$ to imply that the two bipyridinium subunits in a single $\mathrm{CBPQT}^{4+}$ ring are no longer chemically equivalent. However, in the bistable [3] rotaxane $\mathbf{P P R}{ }^{8+}$, another interpretation is possible-namely, that the two $\mathrm{CBPQT}^{4+}$ rings reside in different chemical environments. It is significant that the shapes of the two anodic reoxidation processes are both tall and thin. This behavior is more pronounced at slower scan rates of around $10 \mathrm{mV} \mathrm{s}^{-1}$ and more or less absent at fast scan rates in the region of $1000 \mathrm{mV} \mathrm{s}^{-1}$ and is assigned to precipitation of the reduced forms on the electrode surface.

The CVs of $\mathbf{P P R}^{8+}$ recorded (Figure 7 ) at $248 \mathrm{~K}$ by contrast to the room temperature studies reveal, not only a stepwise mechanism for the cyclophanes' movements following oxidation of the TTF units, but also the presence of a metastable state. At $1000 \mathrm{mV} \mathrm{s}^{-1}$, two broad overlapping peaks are observed at 900 and $1150 \mathrm{mV}$, when the scan direction of the $\mathrm{CV}$ is switched back at a vertex potential of $+1500 \mathrm{mV}$. Moreover, the characteristic reduction peaks, observed during the cathodic sweep, indicate the return of the dication in a standard fashion, first to the monocation and then subsequently back to the neutral form. The first of the oxidation peaks can be assigned to oxidation and movement of a single $\mathrm{CBPQT}^{4+}$ ring on only one-half of the [3] rotaxane and the second peak to the same process in the other half of the rotaxane. When the $\mathrm{CV}$ is switched at a vertex potential halfway between the two peaks

(50) Asakawa, M.; Ashton, P. R.; Ballardini, R.; Balzani, V.; Belohradsky, M.; Gandolfi, M. T.; Kocian, O.; Prodi, L.; Raymo, F. M.; Stoddart, J. F.; Venturi, M. J. Am. Chem. Soc. 1997, 119, 302-310.
$(+1050 \mathrm{mV})$, the reduction peaks are only half their expected intensities, consistent with oxidation occurring in only one-half of the rotaxane. Moreover, the reduction peak at $700 \mathrm{mV}$, assigned to the dication, can only be present if the dication is formed after the first of the two oxidation processes.

In addition, the second cycle of the fast-scan rate $\mathrm{CV}$ at 248 $\mathrm{K}$ reveals a small peak at $570 \mathrm{mV}$ that is assigned to a small proportion $(<5 \%)$ of the switched metastable state ${ }^{49}$ remaining after $0.9 \mathrm{~s}$. Consequently, the movement of the ring back to the TTF unit is estimated to relax over a free energy barrier of less than $14 \mathrm{kcal} \mathrm{mol}^{-1}$. Attempts to erase ${ }^{51}$ the metastable state by reducing the $\mathrm{CBPQT}^{4+}$ rings at $\sim-400 \mathrm{mV}$ during the $\mathrm{CV}$ cycle were effective for the singly switched half but not when both sides are oxidatively switched. A full quantitative analysis of the metastable state in solution was not possible with such low barriers.

The bistable [2]rotaxane $\mathbf{1 5}^{4+}$ displays (Figure 6b) a complex $\mathrm{CV}$ that is, quite simply, a linear combination of half of the [3] rotaxane $\mathbf{P P R}^{8+}$ and the dumbbell PPD. The oxidation region of the $\mathrm{CV}$ displays a redox couple of the bare dumbbell-like TTF unit (oxidation and reduction, $E_{1 / 2}=+340 \mathrm{mV}$ ) that is achieved at a similar potential to that of the dumbbell. The second oxidation peak at $+760 \mathrm{mV}$ corresponds to the peak observed for the [3] rotaxane $\mathbf{P P R}{ }^{8+}$, and it can be assigned to a three-electron process in which two electrons are removed from the encircled TTF unit and one from the bare monocation $\mathrm{TTF}^{+} \bullet$. The reduction process at $+675 \mathrm{mV}$ corresponds closely to that noted for $\mathbf{P P R}{ }^{8+}$ and can be assigned to the reformation the monocationic $\mathrm{TTF}^{+} \bullet$ units at both ends of the rotaxane. The peak at $+410 \mathrm{mV}$ can be assigned to the reduction of the $\mathrm{TTF}^{+} \cdot$ monocation back to its neutral form, producing a metastable state at one end of the [2]rotaxane that is in a dynamic equilibrium with the ground state. The reduction of the $\mathrm{CBPQT}^{4+}$ ring is similar to that observed for both the [3]rotaxane $\mathbf{P P R}^{8+}$ and the free $\mathrm{CBPQT}^{4+}$ cyclophane. However, the fully reduced state $\mathbf{1 5}^{0}$ appears to become precipitated onto the electrode.

UV/Visible Spectroelectrochemistry. The UV-visible spectroscopic changes (Figure 8) associated with the electrochemical oxidation processes of $\mathbf{P} \mathbf{P R}^{8+}$ were recorded in order to identify the mechanical location of the $\mathrm{CBPQT}^{4+}$ cyclophanes, as well as the mechanism of switching. The observed changes are compared to those of the dumbbell PPD in order to identify these changes that are solely associated with the mechanically mobile cyclophanes. The ground-state UV-visible spectrum of $\mathbf{P P R}^{8+}$ displays (Figure 8a) the characteristic ${ }^{52}$ charge-transfer band at $850 \mathrm{~nm}$ assigned to the $\mathrm{TTF} \rightarrow \mathrm{CBPQT}^{4+}$ electronic transition. Upon oxidation over the potential range 650-730 $\mathrm{mV}$ employing a controlled-potential protocol, the ground-state bands bleach and are replaced by characteristic bands in the visible region at 600 and $450 \mathrm{~nm}$ that signify the formation of the two monocations, $\mathrm{TTF}^{+} \cdot$. Concomitant with the changes in the visible region, the $\mathrm{UV}$ band at $360 \mathrm{~nm}$, assigned to a $\pi-\pi^{*}$ transition of the conjugated naphthalene phenylenevinylene core, is observed to red-shift and to lose some of its intensity. These

(51) Tseng, H. R.; Wu, D.; Fang, N.; Zhang, X.; Stoddart, J. F. ChemPhysChem 2004, 5, 111-116.

(52) Asakawa, M.; Ashton, P. R.; Balzani, V.; Credi, A.; Hamers, C.; Mattersteig, G.; Montalti, M.; Shipway, A. N.; Spencer, N.; Stoddart, J. F.; Tolley, M. S.; Venturi, M.; White, A. J. P.; Williams, D. J. Angew. Chem., Int. Ed. 1998, 37, 333-337. 


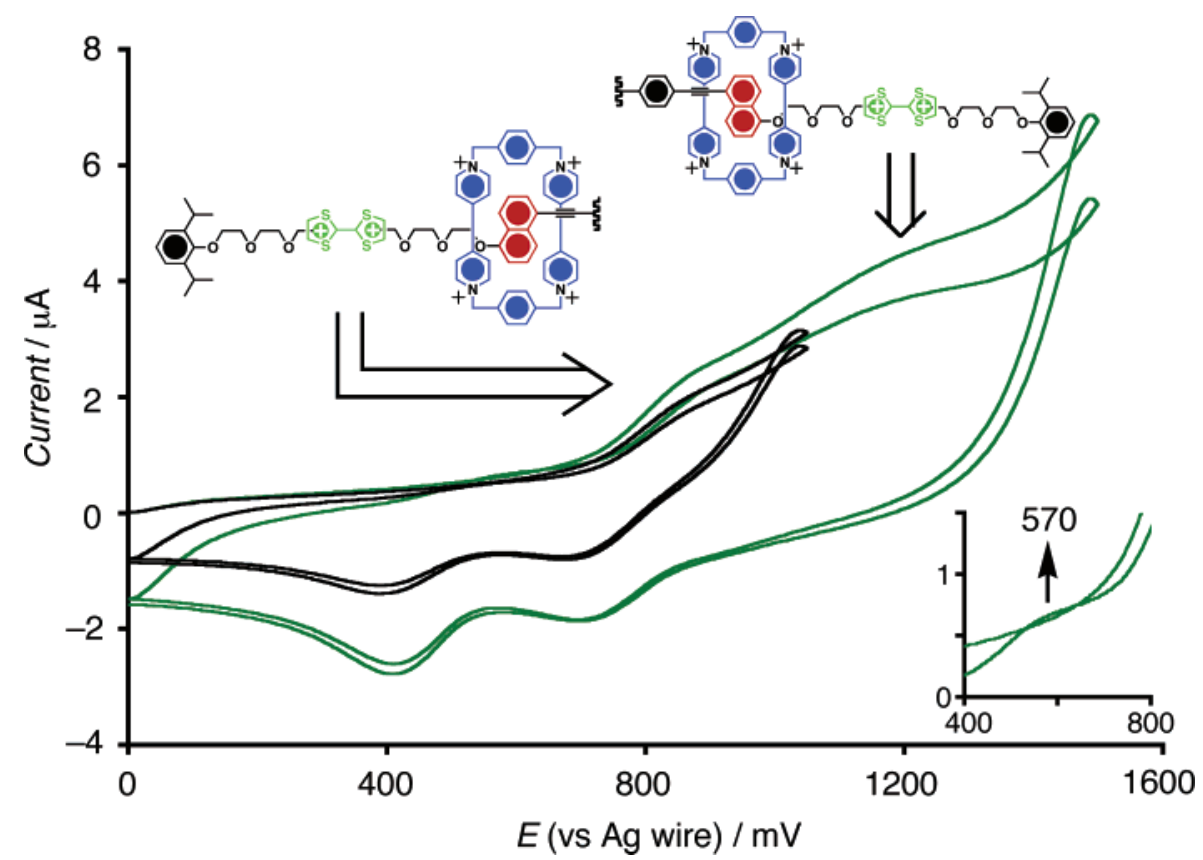

Figure 7. Cyclic voltammetry of the molecular muscle $\mathbf{P P R}^{8+}$ recorded at a low temperature $(248 \mathrm{~K})$ and at a fast scan rate $\left(1000 \mathrm{mV} \mathrm{s} \mathrm{s}^{-1}\right)$ with two different vertex potentials. The inset shows a small peak at $570 \mathrm{mV}$ has grow-in for the second cycle of the $\mathrm{CV}$.

changes indicate that the $\pi-\pi^{*}$ transition is sensitive to the movement of the two rings to encircle the NP rings systems. After holding the potential at $730 \mathrm{mV}$ until all the spectroscopic changes have stopped, a second oxidation process is initiated a mere $10 \mathrm{mV}$ after the first process has ended. The spectra display a bleaching of the $\mathrm{TTF}^{+} \bullet$ bands with formation of a shoulder at $\sim 380 \mathrm{~nm}$ characteristic with the formation of the $\mathrm{TTF}^{2+}$ dication. Bleaching the $\mathrm{TTF}^{+\bullet}$ chromophore reveals a weak band at $520 \mathrm{~nm}$, which is assigned to the $\mathrm{NP} \rightarrow \mathrm{CBPQT}^{4+} \mathrm{CT}$ electronic transition. Moreover, the weakened and red-shifted UV band assigned to the rigid NP-based core of the dumbbell does not alter. Both of these observations indicate that the $\mathrm{CBPQT}^{4+}$ cyclophanes have relocated to the NP ring systems and that their movements occurred after the initial formation of the $\mathrm{TTF}^{+} \cdot$ monocations.

By comparison, the dumbbell-only component, PPD, displays (Figure 9) much simpler spectroscopic changes that occur at well-separated oxidation potentials. The spectroscopic changes were recorded at the beginning of $60 \mathrm{mV}$ windows during a slow scan rate $\left(0.5 \mathrm{mV} \mathrm{s}^{-1}\right) \mathrm{CV}$ in an optically transparent thinlayer electrochemical cell. The thin layer CV displays (inset to Figure 9) the same features as the solution CV. The first oxidation process generates the $\mathrm{TTF}^{+\bullet}$ state, $\mathbf{P P D}^{2 \bullet / 2+}$, evidenced by the visible bands at 450 and $600 \mathrm{~nm}$. There are no changes observed in the UV band of the rigid core at $360 \mathrm{~nm}$ that were otherwise observed for the [3]rotaxane. The second oxidation is verified by the bleach in the visible region and growth of the shoulder at $400 \mathrm{~nm}$ with a weak shoulder revealed at $440 \mathrm{~nm}$. The spectrum is flat at $510 \mathrm{~nm}$ attesting to the absence of the mechanically mobile $\mathrm{CBPQT}^{4+}$ cyclophanes. The returning cathodic sweep of the $\mathrm{CV}$ through the two reductions generates spectroscopic changes that are virtual facsimiles of those observed throughout the anodic sweep. In a separate experiment that utilizes a controlled-potential protocol, the spectroscopic changes of PPD were the same as those observed using the slow scan-rate CV protocol (Figure 9). It is noteworthy that the first oxidation of PPD $(400-500 \mathrm{mV}$ ) recorded in the controlled-potential experiment is well-separated by $350 \mathrm{mV}$ from the second oxidation $(850-1000 \mathrm{mV})$ by comparison to $\mathbf{P P R}^{8+}$, which exhibits almost no separation $(10 \mathrm{mV})$ at all. This difference indicates that the presence of the tetracationic rings significantly alter the oxidation potentials of the TTF units and is a spectroelectrochemical observation that is consistent with the CV.

The spectroelectrochemistry of the [2] rotaxane $\mathbf{1 5}^{4+}$ was recorded throughout the single cycle of a $\mathrm{CV}\left(0.5 \mathrm{mV} \mathrm{s}^{-1}\right)$. The linear combination of the dumbbell and rotaxane halves observed in the solution-phase CV is represented (Figure 10, insets) in the thin-layer CV with concomitant spectroscopic changes. The distinct (Figure 10a) TTF-based oxidation of the dumbbell end, observed at $+400 \mathrm{mV}$, is followed in the UVvisible spectrum by a bleach at $300 \mathrm{~nm}$ and the growth of the monocation based visible bands, although the $850 \mathrm{~nm} \mathrm{CT}$ band is completely unaltered. Subsequently, a shoulder in the CV at $700 \mathrm{mV}$ is unambiguously assigned to the mono-oxidation of the rotaxane end by the UV-visible changes; i.e., the $850 \mathrm{~nm}$ CT band is finally bleached and (Figure 10b) the $\mathrm{TTF}^{+}$. chromophore doubles in its intensity from 0.25 to 0.50 . The oxidation to the dicationic form occurs simultaneously (Figure 10c) at each end of the [2] rotaxane producing only a weak NP $\rightarrow \mathrm{CBPQT}^{4+}$ band at $510 \mathrm{~nm}$ assigned to the single CT chromophore. The anodic return to the monocation is a reverse of the dications' formation. The rotaxane end is reformed at $550 \mathrm{mV}$ although the spectroscopic changes are not so well resolved from those of the dumbbell end at $350 \mathrm{mV}$. It is noted that the $\mathrm{CV}$ of the thin-layer spectrolectrochemical cell corresponds to that $\mathrm{CV}$ recorded in bulk solution with a scan rate of $8 \mathrm{mV} \mathrm{s}^{-1}$, indicating the usefulness of the spectroelectrochemical technique for assigning features in the $\mathrm{CV}$.

In summary, the solution-phase $\mathrm{CV}$ and the spectroscopic changes following the oxidation and reduction cycle of the [3]rotaxane, its dumbbell and the [2]rotaxane are self-consistent 


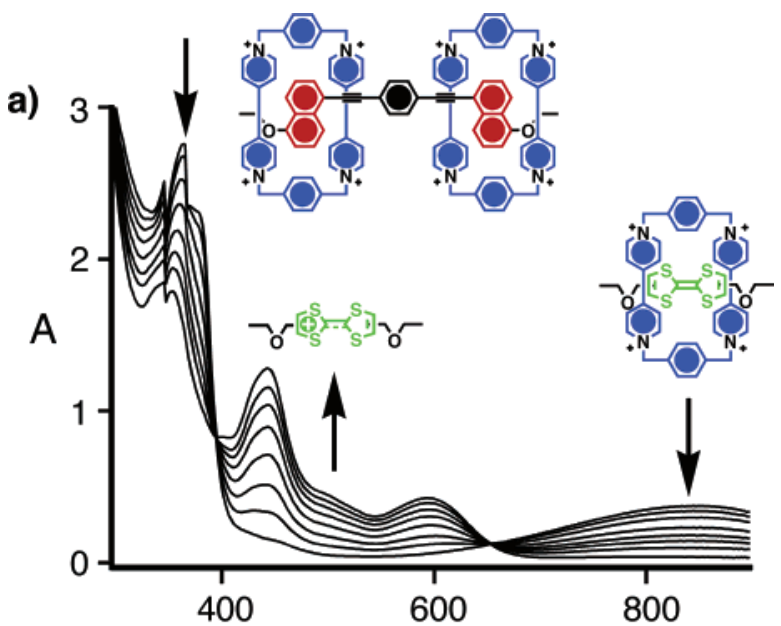

b)

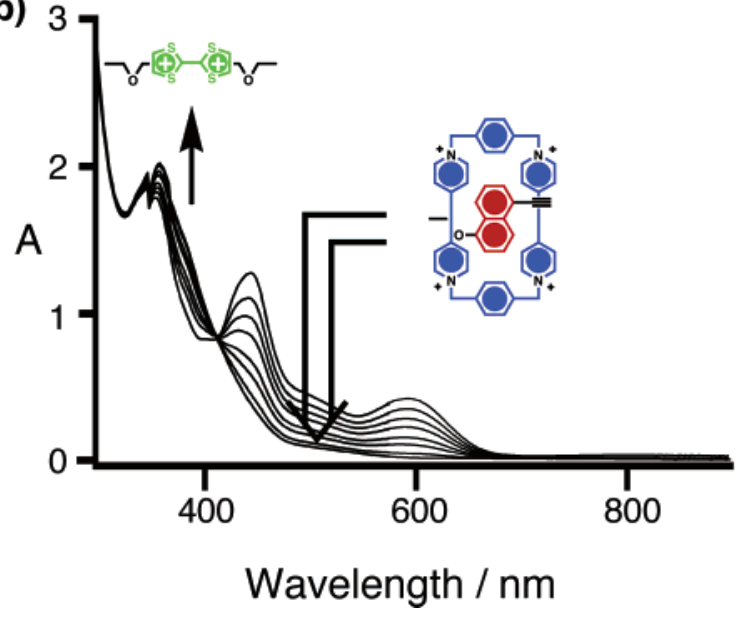

Figure 8. UV-visible spectroelectrochemistry of $\mathbf{P P R}^{8+}\left(\sim 0.3 \times 10^{-3}\right.$ mol L ${ }^{-1}, \mathrm{MeCN}, 0.1 \mathrm{~mol} \mathrm{~L}^{-1} \mathrm{TBAPF}_{6}$ ) recorded over a range of potentials in order to resolve (a) the formation of the TTF-based monocationic and switched form $(650-730 \mathrm{mV})$ and then (b) the formation of the corresponding dicationic forms $(>730 \mathrm{mV})$. The chromophoric components responsible for each absorption are marked.

and attest to the movement of the cyclophane(s) following oxidation of the TTF unit(s). For PPR ${ }^{8+}$, the spectroelectrochemistry confirms the movement of the cyclophanes after the first oxidation, and for $\mathbf{1 5}^{4+}$, the assignment of each of the oxidation redox processes were unambiguously distinguished. In addition, the mechanism of mechanical switching of the molecular muscle can be changed (Scheme 4) from concerted at ambient temperatures to one that operates in a stepwise manner at cryogenic temperatures.

Mechanical Actuation of Cantilever Arrays Using Molecular Muscles. The reversible chemical switching of $\mathbf{P} \mathbf{P R}{ }^{8+}$ in solution provided a basis for the design (Figure 11a) of a chemomechanical actuator ${ }^{7}$ utilizing the linear molecular muscle TPR $^{8+}$ self-assembled by $\mathrm{Au}-\mathrm{S}$ bonds onto cantilever beams. The oxidation-induced contraction of the inter-ring distance generated a tensile stress that was transduced to the underlying substrate through the tethers. The resulting cumulative effect of a randomly oriented ensemble of 6 billion molecular muscles in a SAM on the cantilever beam, produced an upward mechanical bending of the beam. Subsequently, reductioninduced extension of the inter-ring distance in $\mathbf{T P R}{ }^{8+}$ was observed to relieve the stress upon the beam, thus resulting in

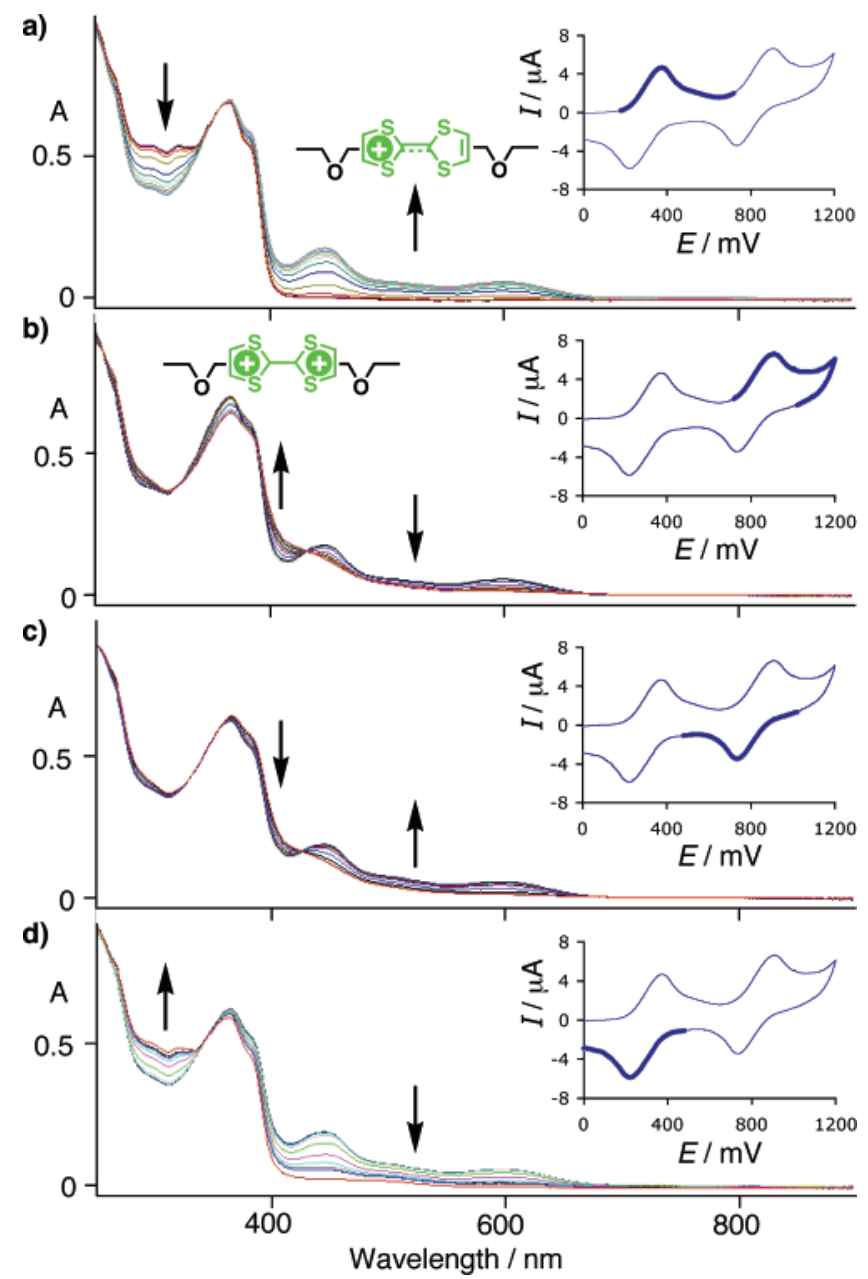

Figure 9. UV-visible spectroelectrochemistry of the dumbbell PPD $(\sim 1$ $\times 10^{-3} \mathrm{~mol} \mathrm{~L}^{-1}, \mathrm{CH}_{2} \mathrm{Cl}_{2}, 0.1 \mathrm{~mol} \mathrm{~L}^{-1} \mathrm{TBAPF}_{6}$ ) recorded simultaneously with a $\mathrm{CV}$ (inset, $0.2 \mathrm{mV} \mathrm{s}^{-1}$ ) showing the corresponding growth and bleach of the related chromophores. The voltage ranges that account for the spectroscopic changes are marked on the $\mathrm{CV}$ in bold and correspond to the formation of TTF-based (a) monocations $\mathbf{P P D}^{2 \cdot / 2+}$ and (b) dications $\mathbf{P} \mathbf{P D}^{4+}$ together with the reverse reformation of (c) the monocations and (d) neutral forms.

a downward motion and a return to the beam's original equilibrium position.

Briefly, a silicon cantilever array coated on its topside with a $20 \mathrm{~nm}$ thin layer of gold was coated ${ }^{2}$ with the muscle molecules and placed in the transparent fluid cell of a Digital Instruments Scentris Research Tool modified for the deflection experiments. No attempt was made to align the molecules in the monolayer, thus determining that only the component of the contraction that is aligned with the long axis of the cantilever contributes effectively to the beam's bending. Aqueous Fe$\left(\mathrm{ClO}_{4}\right)_{3}$ (oxidant) and ascorbic acid (reductant) solutions were sequentially and alternatively introduced into the fluid cell under constant flow $(250-300 \mu \mathrm{L} / \mathrm{min})$. The deflection of the beams versus time (Figure 11) indicate that synchronous with addition of the oxidant solution $(1.0 \mathrm{mM})$, all four cantilever beams (Figure 10b, only one beam deflection is shown) bend upward by ca. $35 \mathrm{~nm}$ to an apparent saturation point in $1 \mathrm{~min}$. Introduction of the reductant solution $(2.0 \mathrm{mM})$ caused the cantilever beams to bend back downward to their starting positions. In the original study, a number of the alternative factors that could lead to synchronous deflection were dis- 


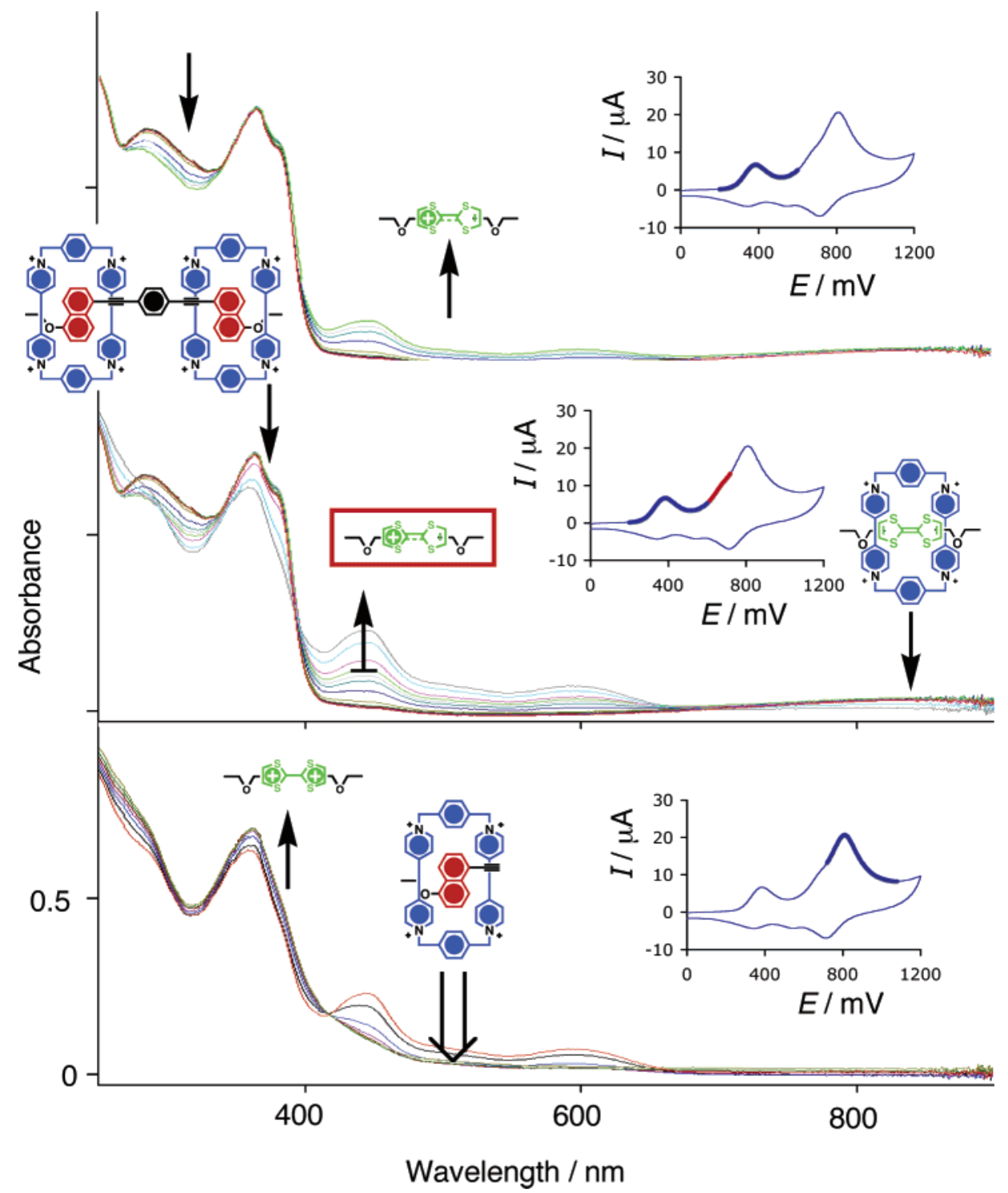

Figure 10. UV-visible spectroelectrochemistry of the [2]rotaxane $\mathbf{1 5}^{4+}\left(\sim 0.3 \times 10^{-3} \mathrm{~mol} \mathrm{~L}^{-1}, \mathrm{MeCN}, 0.1 \mathrm{~mol} \mathrm{~L}^{-1} \mathrm{TBAPF}_{6}\right) \mathrm{recorded}$ simultaneously with a CV (inset, $0.2 \mathrm{mV} \mathrm{s}^{-1}$ ) showing the corresponding growth and bleach of the related chromophores. The voltage ranges that account for the spectroscopic changes are marked on the $\mathrm{CV}$ in bold and correspond to the stepwise formation of the TTF-based (a) monocation of the dumbbell-like end $\mathbf{1 5}^{\circ / 3+}$ of the [2]rotaxane and the (b) monocationic and switched form of the rotaxane-like end $\mathbf{1 5}^{\mathbf{2} / 2+}$ followed by formation of the (c) dicationic form at both ends $\mathbf{1 5}^{4+}$.

counted. $^{7}$ A control compound TPD bearing disulfide tethers at either end was tested under identical conditions (Figure 11c) and revealed that changes in the electrostatic charge, conformational rearrangements, and thermal effects do not bend the beams. $\mathrm{pH}$ Changes were found to contribute insignificantly using an experimental setup with the molecular muscle. Photothermal effects would be insignificant with such small laser beam diameters $(\sim 3 \mu \mathrm{m})$. In any event, these alternative factors would more likely bend the beam downward in marked contrast to what is observed.

The binary bending behavior was observed for 25 cycles with a noticeable decrease of the magnitude of the beam bending. This effect may be attributed to one or a combination of gradual chemical and/or physical passivation of the SAM including chemical degradation of the molecular muscle, movement of individual gold atoms, and/or the $\mathrm{S}-\mathrm{Au}$ attachment sites by virtue of the dynamic self-assembly process. ${ }^{53}$ Nevertheless, the

(53) Ulman, A. An Introduction to Ultrathin Organic Films From LangmuirBlodgett to Self-Assembly; Academic Press: San Diego, 1991. movement of the cantilever beams is directly correlated with the cycling of the oxidant and reductant solutions. While it may be possible for any number of the heretofore unobserved (yet reversible) molecular conformational rearrangements to take place within the molecules or within the monolayer's structure, the simplest explanation lies with the collective effect of molecular-scale contraction and extension of the inter-ring distance in the [3]rotaxanes. This result suggests that the cumulative effect of individual molecular-scale motions within disulfidetethered [3] rotaxane molecules, even when randomly aligned, can be harnessed to perform larger-scale mechanical work.

To gain a more quantitative understanding of the chemomechanical transduction and amplification process, the beams' deflection was analyzed based on the molecular force generated from the contraction of the molecular muscle. The mean molecular force of each individual $\mathrm{TTF}^{2+} / \mathrm{CBPQT}^{4+}$ interaction can be calculated based on Coulomb's law

$$
F=q_{1} q_{2} / 4 \pi \epsilon_{0} \epsilon r^{2}
$$


Scheme 4. Electrochemically-Stimulated Switching Cycle from Extended to Contracted Forms of PPR ${ }^{8+}$ under Normal Conditions as Well as at Slow and Fast Switching Speeds (superscripts on the square brackets relate to intermediates (I) and metastable states (MS))

Slow

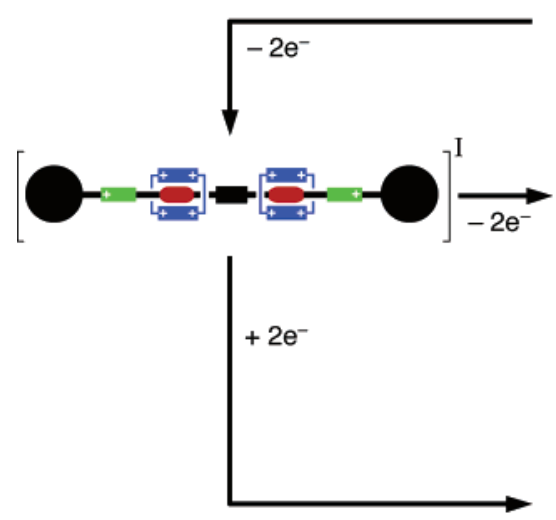

Normal

Fast

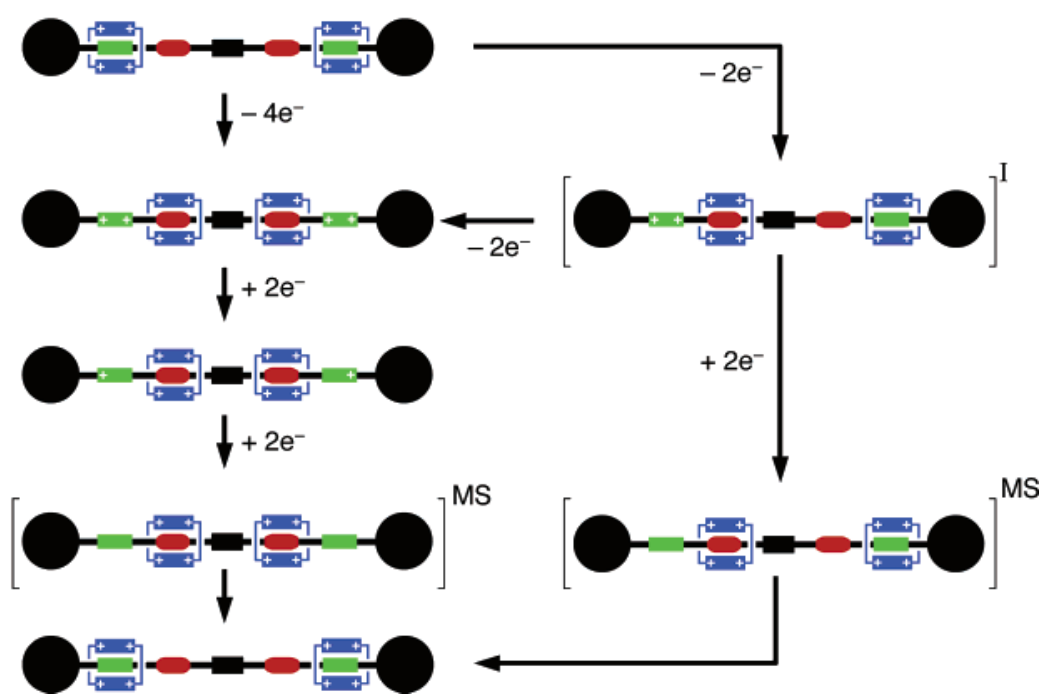

where $F$ is the instantaneous electrostatic force that exists between two charges, $q_{1}(+2)$ and $q_{2}(+4)$, that are a distance $r$ apart from each other within a surrounding medium of dielectric $\epsilon\left(80, \mathrm{H}_{2} \mathrm{O}\right)$ and where $\epsilon_{0}$ is the permittivity of free space. One-half of the rotaxane system was modeled by placing (Figure 12a) four positive charges distributed evenly on a ring with two positive charges located at the ring's center. The total force and its $x$-component $\left(F_{x}\right)$ aligned along the dumbbell was calculated as a function of the distance along the dumbbell.

$$
F_{x}=F \times x / r
$$

where

$$
r^{2}=x^{2} \times R^{2}
$$

in which $x$ is the distance along the dumbbell and $R$ is the radius of the tetracationic ring. The rotaxane in an idealized linear conformation of the dumbbell can be considered as an upper limit for the force that can be produced in a single molecular muscle. The maximum mean force $F_{\mathrm{m}}$ was determined by integrating the area under the force curve $\left(F_{x}\right)$ from 0 to 1.4 $\mathrm{nm}$ and then dividing this value by the distance that the ring moves, $1.4 \mathrm{~nm}$. As a means to consider how the force would change if the dumbbell component of the molecular muscle begins in a folded state on account of side-on interactions with the NP stations and favorable H-bonding with the intervening diethylene glycol spacer, a second minimum-force scenario was evaluated (Figure 12). In this case, the oxidized, surface-bound compound $\mathbf{T P R}^{12+}$ is expected to be linear to reduce any Coulombic repulsion. This transformation is akin to the net movement of the ring from its origin toward the NP site by 0.6 $\mathrm{nm}$ (equivalent to twice the $\pi-\pi$ stacking distance) coupled with a movement of the $\mathrm{TTF}^{2+}$ unit $0.8 \mathrm{~nm}$ away from the origin. Consequently, the final linear conformational arrangement of the molecular muscle is used to approximate the minimum mean force by integrating the area under the curve from 1.4 to $0.8 \mathrm{~nm}$. Finally, the dielectric constant for the aqueous solution is assumed to remain unaffected ${ }^{54}$ on the addition of $1-2 \mathrm{mM}$ of the redox reagent and thus equivalent to water $(\epsilon=80)$. Any specific ion pairing is assumed to be negligible, given the aqueous solubilities of the $\mathrm{ClO}_{4}{ }^{-}$counterions that will be present in exchange ${ }^{10 \mathrm{e}}$ for the $\mathrm{PF}_{6}{ }^{-}$anions. On balance, while the tetracationic rings come within $1.4 \mathrm{~nm}$

a)
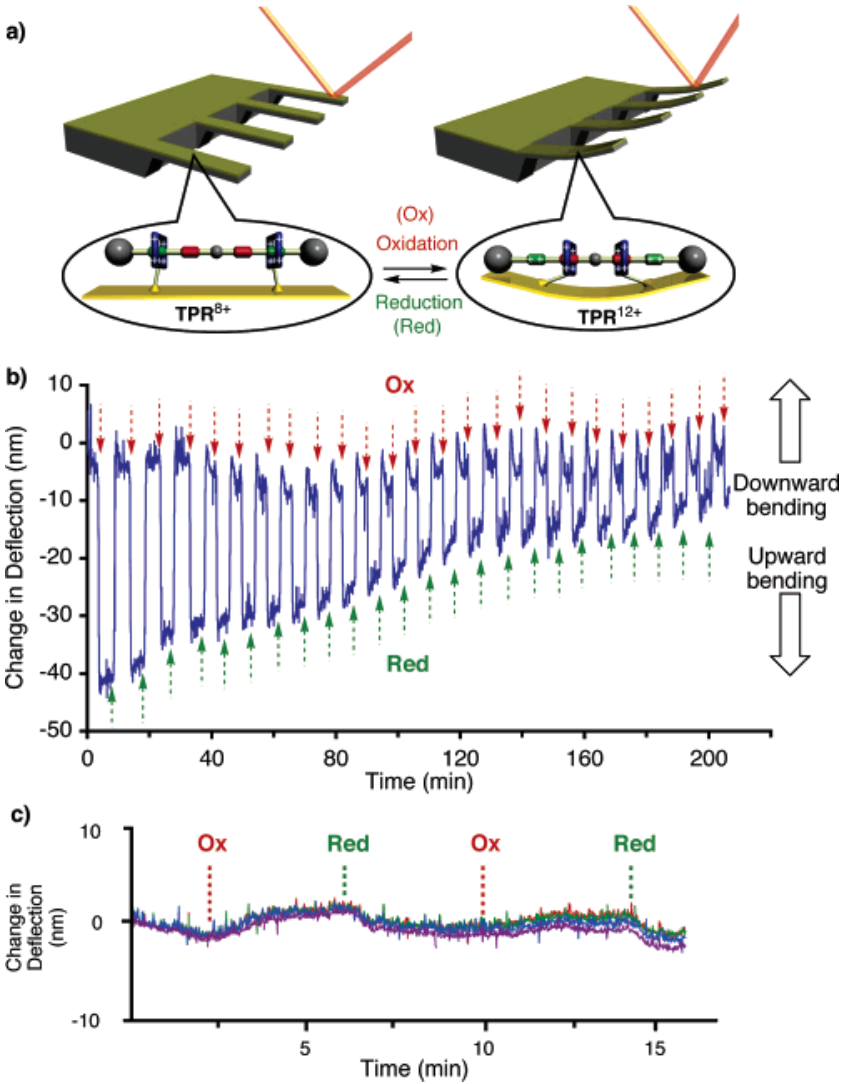

Figure 11. (a) Schematic diagram of the proposed mechanism of the device's operation. Experimental data showing (b) 25 cycles of the upward and downward bending of one cantilever beam coated with $\mathbf{T P R}^{8+}$ and (c) the limited deflection of the cantilever array coated with the control dumbbell compound TPD under alternative oxidation and reduction conditions. The red and green arrows indicate the time when oxidant or reductant solution is injected into the fluidic cell. A negative deflection corresponds to an upward bending of the cantilever beams. 


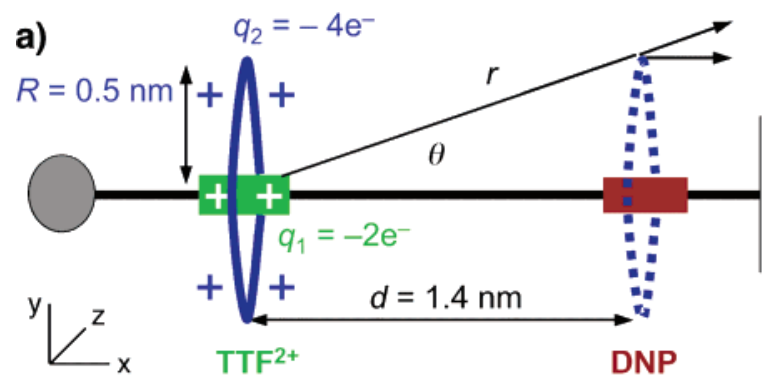

b)

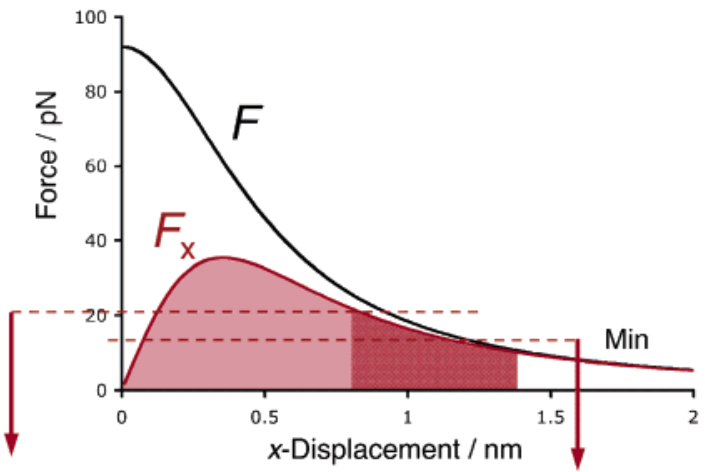

c)
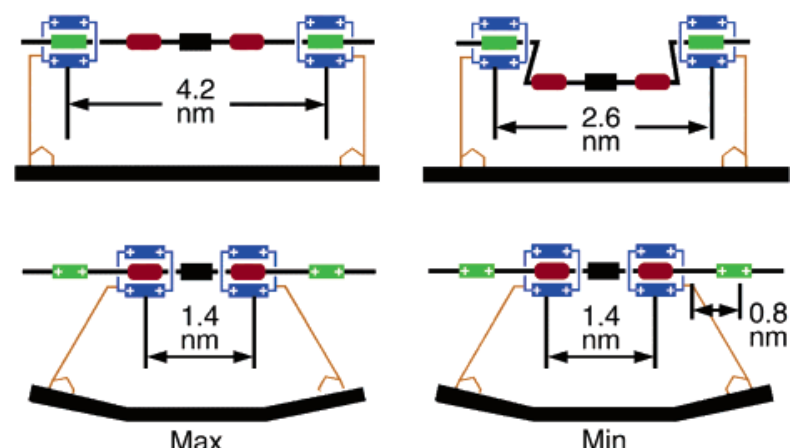

Figure 12. The electrostatic force produced from one end of the rotaxane can be estimated on the basis of (a) a simple model describing the geometry and charges present from which can be derived and (b) a graph that describes how the total and $\mathrm{x}$-component force changes depending on the distance between the tetracationic ring (4+) and the origin of the $\mathbf{T} \mathbf{T F}^{2+}$ charges. (c) The maximum and minimum force can be estimated from the two reasonable extremes of the surface-bound molecular muscle's conformation. In the maximum, the rings move the largest distance, whereas for the minimum-force case, the rings close up only a little while the dumbbell becomes elongated.

of each other, the ${ }^{1} \mathrm{H}$ NMR spectroscopic study (Figure 4, 233 K) reveals that they have $>95 \%$ occupancy on the NP sites.

These two scenarios for the mean molecular force determine the maximum and minimum values of 21 and $14 \mathrm{pN}$ from which it is possible to calculate theoretically how much the cantilever beam of the dimension $(500 \times 100 \times 1 \mu \mathrm{m})$ and spring constant $\left(0.02 \mathrm{~N} \mathrm{~m}^{-1}\right)$ should bend when it is covered completely by 6 billion molecular muscles that are randomly aligned yet all switching simultaneously. A mechanical analysis, akin to the analysis of stresses and strains in plate tectonics, ${ }^{55}$ reveals ${ }^{7}$ that the collective effect of the generated molecular forces can generate a bending moment, which will result in an out-of-plane beam displacement with a maximum and minimum magnitude

(54) Hubbard, J. B.; Onsager, L.; Vanbeek, W. M.; Mandel, M. Proc. Natl. Acad. Sci. U.S.A. 1977, 74, 401-404.

(55) Turcotte, D. L.; Schubert, G. Geodynamics; Cambridge University Press: Cambridge, 2002. of 50 and $34 \mathrm{~nm}$, respectively, which is in good agreement with the experimental result $(35 \mathrm{~nm})$.

Alternatively, from the force constant of the cantilever and the measured deflection, the force per molecule can be estimated (Supporting Information), based on simple geometrical assumptions and continuum calculations related to Hooke's law. Given a deflection of $35 \mathrm{~nm}$, the force per molecule is $10.2 \mathrm{pN}$. This value is in the order of magnitude of the force calculated as a result of electrostatic interactions within each molecular muscle, although smaller in magnitude. This observation is reasonable since, in this analysis, the tension is assumed to be uniformly distributed on the top surface of the cantilever. This assumption is not strictly true since tension only occurs between the anchors of the two rings, so that the forces required of each surfacebound [3]rotaxane is greater than what has been calculated. These calculations reveal that the top surface of the beam shortens by $0.14 \mathrm{~nm}$ corresponding to an average compression of $0.001 \mathrm{pm}$ per molecule between the anchoring points of the rings.

Given that the time required for the beams to bend is attributed to mixing within the solution, it is difficult to analyze the mechanistic details of the molecular muscle's contraction and extension. Nevertheless, one could consider a number of possible scenarios. Primarily, the rings move in order to minimize Coulombic forces (push). They are believed to move toward the NP donor stations because (1) they can bind with the NP stations (pull), a situation that will additionally (2) mediate the four positive charges on each ring on account of favorable charge-transfer mixing. This inter-ring contraction is counterbalanced by the cantilever's spring constant and thus the movements of the individual rings in molecular muscles may well occur in an stepwise fashion, one ring first and then the other, in a thermally activated process until each molecular movement is complete. Beyond such considerations about the mechanism of the chemomechanical transduction, it remains unambiguous that the surface-bound mechanically mobile rings are essential for the beam's bending.

\section{Conclusions}

Artificial molecular motors, based on a palindromic [3]rotaxane constitution, have been constructed and shown subsequently to display a unique biomimicry of natural muscles. ${ }^{1} \mathrm{H}$ NMR spectroscopic and UV-visible spectroelectrochemical experiments show clearly that the voltage-addressable oxidation/ reduction cycle of the TTF unit can control precisely the locations of the two ring components of a palindromic [3]rotaxane along its dumbbell-shaped component. At normal electrochemical stimulation speeds, the extended inter-ring state becomes contracted when each TTF unit is dicationic. At slower stimulation speeds, the monocationic forms can be identified. At low temperatures and faster speeds, the two rings move stepwise from their respective ends of the rotaxane and the metastable state relaxes much faster than $10 \mathrm{~s}^{-1}$ at $248 \mathrm{~K}$. The ring movements under redox conditions provide an optimal change of $2.8 \mathrm{~nm}$ in terms of the inter-ring distance, representing a strain of $67 \%$ with respect to the original inter-ring distance. The ability to control the movement of the rings between the two switched states in response to external stimuli makes this molecule an excellent candidate for constructing a molecular device. Disulfide tethers attached to the rings enable the 
anchoring of molecular motors to solid substrates. By formation of a SAM on the gold surface of an array of microcantilever beams, the molecular motors are incorporated into a NEMS device that undergoes controllable and reversible bending as they are subjected to chemical oxidants and reductants. Control studies indicate that it is the contraction and extension of the surface-bound nanoscale molecular muscles that lead to the bending of a beam that is five orders of magnitude larger in size. A logical development-by replacing the chemically driven redox process with direct electrical or optical stimulation-would contribute to a technological basis for the production of a new class of multi-scale NEMS devices based upon nanomechanical motion in switchable interlocked molecules.

Acknowledgment. This work was funded in part by a National Science Foundation NIRT grant (ECS-0103559), by
NASA's Institute for Cell Mimetic Space Exploration, and by the Defense Advanced Research Projects Agency (DARPA) Biomolecular Motors program. Some of the compound characterizations are supported by the National Science Foundation under equipment grant numbers CHE-9974928 and CHE0092036. In Denmark, this work was supported by the Danish Natural Science Research Council (SNF, grants 21-03-0014 and 21-03-0317).

Supporting Information Available: Syntheses of all compounds. Detailed analysis of cantilever bending mechanics based on Hooke's law. Complete refs 44 and 45. This material is available free of charge via the Internet at http://pubs.acs.org.

JA051088P 